\title{
Estimation of Employee Stock Option Exercise Rates and Firm Cost*
}

\author{
Jennifer N. Carpenter Richard Stanton Nancy Wallace \\ New York University U.C. Berkeley U.C. Berkeley
}

June 9, 2009

*Financial support from the Fisher Center for Real Estate and Urban Economics and the Society of Actuaries is gratefully acknowledged. We thank Terrence Adamson at AON Consulting for providing some of the data used in this study. Please direct correspondence to carpenter@stern.nyu.edu, stanton@haas.berkeley.edu or wallace@haas.berkeley.edu. 


\begin{abstract}
This paper is the first to perform a comprehensive estimation of employee stock option exercise behavior and option cost to firms. We develop a GMM-based methodology, robust to heteroskedasticity and correlation across exercises, for estimating the rate of voluntary option exercise as a function of the stock price path and of various firm and option holder characteristics. We use it to estimate an exercise function for a sample of 1.4 million employee-option grants to 562,311 employees at 87 publicly-traded firms between 1980-2007. We also estimate the rate of employment termination, which determines forfeitures, cancellations, and forced exercises. We use the estimated exercise and termination functions in a simulation based valuation model to analyze the effect of different firm and option holder characteristics on option value, and show that the true value of these options can differ substantially from values calculated using the usual modified Black-Scholes approximation.
\end{abstract}

JEL classification: G14. 
With the explosive growth of employee stock options in corporate compensation, investors, auditors, and regulators have become increasingly concerned about the cost of these options to shareholders. Recent regulation requiring firms to recognize option cost has intensified the demand for suitable valuation methods. The difficulty is that these are long-lived American options, so their value depends crucially on how employees exercise them. Yet, because employees face hedging constraints, standard option theory does not directly apply. For example, evidence indicates that employees systematically exercise options on non-dividend paying stocks well before expiration (see, for example, Huddart and Lang (1996), Bettis, Bizjak, and Lemmon (2005)), which substantially reduces their value.

Pricing by no arbitrage is still possible as long as the exercise decision generates an option payoff that is subject only to hedgeable risks, such as stock price risk, and diversifiable risks, such as uncertainties that are idiosyncratic across employees. The option valuation problem then reduces to accurately characterizing the option payoffs, that is, the exercise policies of executives. Until recently, however, full-blown estimation has not been possible because of insufficient data and inadequate methodology. Detailed employee option grant, exercise, and cancellation data are proprietary and very difficult to obtain for a large number of firms. In addition, traditional hazard rate models are not suitable for describing voluntary option exercises, where partial and repeated exercise of options from a given grant is the norm.

This paper is the first to perform a complete empirical estimation of employee stock option exercise behavior and option cost to firms.

Reliable estimation of any option exercise model requires a large sample that includes a wide variety of stock price paths. We estimate our model using a comprehensive sample of option exercise grant and exercise data for 1.4 million employee-option grants to 562,311 employees at 87 publicly-traded firms between 1980-2007. The proprietary data were provided by corporate participants in a sponsored research project that was funded by the Society of Actuaries. The methodology presented in this paper is the first step in developing an actuarial science for valuing compensatory stock options, similar to that for pension liabilities.

In our estimation we find that the rate of voluntary option exercise is positively related to the level of the stock price, but not significantly related to volatility, in contrast to what standard theory would predict. In addition, the exercise rate is higher if the stock price is in the 90th percentile of its distribution over the past year or if the option has just vested.

The estimated exercise function, together with a model for involuntary terminations, can be combined with Monte Carlo simulation to calculate the value of these options to shareholders, taking the employees' exercise and termination behavior into account. This approach is similar to the prepayment modeling and valuation methods developed for mortgage-backed 
securities (see, for example, Schwartz and Torous (1989)).

We compare the prices based on our estimation with the modified Black-Scholes (MBS) method suggested as an approximate valuation technique by the Financial Accounting Standards Board (FASB). We find that the MBS approximation can exhibit significant pricing errors, which are even greater for underwater options than at-the-money options.

\section{Previous Literature}

The principles of employee option stock valuation and the need to study exercise behavior are well-understood in the literature. One approach that has been taken is to model the exercise decision theoretically. The employee presumably chooses an option exercise policy as part of a greater utility maximization problem that includes other decisions, such as portfolio, consumption, and effort choice, and this typically leads to early exercise for the purpose of diversification. Papers that develop utility-maximizing models and then calculate the implied cost of options to shareholders include Huddart (1994), Detemple and Sundaresan (1999), Ingersoll (2006), Leung and Sircar (2009), and Carpenter, Stanton, and Wallace (2009).

Combining theory and data, papers such as Carpenter (1998) and Bettis et al. (2005) calibrate utility-maximizing models to mean exercise times and stock prices in the data, and then infer option value. However, these papers provide no formal estimation and the approach relies on the validity of the utility-maximizing models used. Huddart and Lang (1996) and Heath, Huddart, and Lang (1999) provide more flexible empirical descriptions of option exercise patterns, but do not go as far as option valuation. Two recent approaches, Armstrong, Jagolinzer, and Larcker (2006) and Klein and Maug (2009) estimate exercise behavior using a hazard model, but this specification is inappropriate for option valuation because employees exercise random fractions of outstanding option grants.

A number of analytic methods for approximating executive stock option value have also been proposed in the literature. The FASB currently permits using the Black-Scholes formula with the expiration date replaced by the option's expected life. Jennergren and Näslund (1993), Carr and Linetsky (2000)), and Cvitanić, Wiener, and Zapatero (2004) derive analytic formulas for option value assuming exogenously specified exercise boundaries and stopping rates. Hull and White (2004) propose a model in which exercise occurs when the stock price reaches an exogenously specified multiple of the stock price and forfeiture occurs at

an exogenous rate. However, until the accuracy of these methods can be determined, the usefulness of these approximations cannot be assessed. 


\section{Modeling Exercise Behavior}

\subsection{Hazard Rates}

At first sight, it seems natural to use hazard rates to model the exercise of employee stock options, since they have often been used in the finance literature to model apparently similar events, such as mortgage prepayment (see Schwartz and Torous (1989)) and corporate bond default (see, for example, Duffie and Singleton (1999)). ${ }^{1}$ However, whereas it makes sense to think of the prepayment of one mortgage as independent of the prepayment of another, conditional on the level of interest rates, ESOs are typically exercised in blocks. As a result, the exercise of one option in a given grant held by an individual is extremely highly correlated with the exercise of another option in the same grant held by the same individual. It is also quite highly correlated with the exercise of options in other grants held by the same individual. This high degree of correlation between options makes it difficult to use standard econometric techniques, which assume independence between events, to estimate hazard rates at the individual option level. ${ }^{2}$

One attempt to solve this problem was suggested by Armstrong et al. (2006). Instead of using a hazard rate to model the exercise of individual options, they use a hazard rate to model the exercise behavior of an entire grant of options held by an individual. Aggregating in this way gets around the problem of correlation between individual option exercises, but it introduces a new problem. Whereas a hazard rate describes an event with two states - either something has happened, or it has not - the proportion of an option grant that is exercised in a given period is essentially a continuous variable, which can take on any value between zero and one. Armstrong et al. (2006) work with the dummy variable Exercise ${ }_{i, k, t}$, which indicates whether or not employee $i$ exercises at least $25 \%$ of the vested and unexercised options in grant $k$ on day $t$ (and at least $10 \%$ of all options from the grant). This addresses some of the correlation issues described above, but introduces new problems of its own. First, unlike, say, death from a disease, this variable can equal one more than once, so standard hazard rate estimation techniques may not immediately apply. Second, important information is lost in this aggregation process. For example, consider two option holders who have the same likelihood of exercising on any given date, however, option holder 1 always

\footnotetext{
${ }^{1} \mathrm{~A}$ hazard rate is defined as the likelihood (per period) of an option's being exercised in the next instant, conditional on not having being exercised previously. For good introductions to hazard rate analysis, see Cox (1972) or Kalbfleisch and Prentice (1980).

${ }^{2}$ This issue also arises in modeling corporate bond default. One popular solution, when the number of firms involved is small, has been to use "copula functions", which explicitly model this correlation [See, for example, $\mathrm{Li}(2001)]$. However, in our case the number of options (and hence the number of correlation coefficients) is too high to be feasible.
} 
exercises $25 \%$ of the remaining grant whenever he exercises, whereas option holder 2 always exercises $100 \%$ of his remaining options. The conditional probability of a given option's being exercised at any instant is four times as high for options held by option holder 2 versus option 1, so their options will have very different values, yet the Exercise variable modeled by Armstrong et al. (2006) would behave exactly the same way for the two option holders. Their valuation methodology assumes $100 \%$ of a given vesting tranche is exercised at the hazard rate estimated for exercises in excess of 25\%, an inconsistency which would appear to overstate the rate of early exercise and understate option value. Klein and Maug (2009) use a similar approach, counting exercises as events if the fraction exercised out of a given vesting tranche exceeds a pre-specified threshold, and thus fail to model the distribution of the fraction exercised. Moreover, they do not appear to account for the correlation between exercises of different vesting tranches from the same grant.

\subsection{Modeling Fractional Exercise}

A solution to all of the problems above is to abandon the hazard rate approach altogether and instead to model the fraction of each grant exercised each period. Heath et al. (1999) follow this approach, regressing the fraction of each grant exercised against various explanatory variables. However, their regression approach has some problems. In particular, it may generate expected exercise fractions that are negative or greater than one, both of which cause problems for valuation. ${ }^{3}$ One possible solution is to transform the proportion exercised, such as by using a logistic transformation,

$$
\log \left(\frac{y}{1-y}\right)
$$

which can take on any value between $-\infty$ and $+\infty$, and use this on the right hand side of the regression. Unfortunately, by Jensen's inequality, the expected proportion exercising is not just the inverse transformation of the expected transformed proportion. More important, this approach cannot handle the numerous dates on which no options are exercised at all. Heath et al. (1999) also aggregate across individuals, thus discarding potentially important information about the differences in exercise behavior across individuals.

Like Heath et al. (1999), we also model the fraction of each grant exercised by each holder each period, but we do so in a manner that generates consistent estimates of expected exercise rates that are guaranteed to be between zero and one, while explicitly handling the correlation between option exercises within and between different grants held by the same

\footnotetext{
${ }^{3}$ Attempting to remedy this, for example by truncating the variables, will lead to biases.
} 
individual. Our approach, based on the fractional logistic approach of Papke and Wooldridge (1996), also allows for arbitrary heteroskedasticity in the exercise rates.

Let $y_{i j t}$ be the fraction exercised at time $t$ of grant $j$ held by individual $i$, and write

$$
y_{i j t}=G\left(X_{i j t} \beta\right)+u_{i j t}
$$

where $X_{t}$ is some set of covariates in $I_{t}$, the information set at date $t$, where $G$, the expected fraction exercised at date $t$, is a function satisfying $0<G(z)<1$, and where

$$
\begin{aligned}
E\left(u_{i j t} \mid I_{t}\right) & =0, \\
E\left(u_{i j t} u_{i^{\prime} j^{\prime} t^{\prime}}\right) & =0 \text { if } i \neq i^{\prime} \text { or } t \neq t^{\prime} .
\end{aligned}
$$

From now on, we shall use the logistic function,

$$
G\left(X_{i j t} \beta\right)=\frac{\exp \left(X_{i j t} \beta\right)}{1+\exp \left(X_{i j t} \beta\right)},
$$

which takes on only values between zero and one. Note that, while we are assuming the residuals $\epsilon_{i j t}$ are uncorrelated between individuals and across time periods, we are allowing for $\epsilon_{i j t}$ to be arbitrarily correlated between different grants held by the same individual at a given point in time, and we are not making any further assumptions about the exact distribution of $\epsilon_{i j t}$, or even about its variance. In particular, unlike assuming a beta distribution for $y_{i j t}$ (see Mullahy (1990) or Ferrari and Cribari-Neto (2004)), we are allowing a strictly positive probability that $y_{i j t}$ takes on the extreme values zero or one.

As in Papke and Wooldridge (1996), we estimate the parameter vector $\beta$ using quasimaximum likelihood (see Gouriéroux, Monfort, and Trognon (1984)) with the Bernoulli log-likelihood function,

$$
l_{i j t}(\beta)=y_{i j t} \log \left[G\left(X_{i j t} \beta\right)\right]+\left(1-y_{i j t}\right) \log \left[1-G\left(X_{i j t} \beta\right)\right] .
$$

Estimation involves solving

$$
\max _{\beta} \sum_{i, j, t} l_{i j t}(\beta) .
$$


The $K$ first order conditions, corresponding to the $K$ elements of $\beta$, are given by

$$
\begin{aligned}
\sum_{i, j, t} \frac{d l_{i j t}(\beta)}{d \beta} & =\sum_{i, j, t} X_{i j t}\left[G^{\prime}\left(X_{i j t} \beta\right)\left(\frac{y_{i j t}}{G\left(X_{i j t} \beta\right)}-\frac{1-y_{i j t}}{1-G\left(X_{i j t} \beta\right)}\right)\right] \\
& =\sum_{i, j, t} X_{i j t}\left(y_{i j t}-G\left(X_{i j t} \beta\right)\right) \\
& =0 .
\end{aligned}
$$

Equation (1) implies (using iterated expectations) that the population expectation of these first order conditions is zero, hence this QML estimator, $\widehat{\beta}$, is a (consistent) GMM estimator of $\beta$, with no assumptions other than Equation (1). Following the notation in Papke and Wooldridge (1996), define the residual

$$
\widehat{u}_{i j t} \equiv y_{i j t}-G\left(X_{i j t} \widehat{\beta}\right)
$$

and define

$$
\widehat{g}_{i j t} \equiv G^{\prime}\left(X_{i j t} \widehat{\beta}\right)
$$

To allow for heteroskedasticity and for correlation between option grants held by a given individual, write

$$
\operatorname{var}(u)=\Omega=\left(\begin{array}{ccccc}
\Sigma_{1} & & \ldots & & 0 \\
& \ddots & & & \\
\vdots & & \Sigma_{i} & & \vdots \\
& & & \ddots & \\
0 & & \ldots & & \Sigma_{I}
\end{array}\right)
$$

where each $\Sigma$ block corresponds to all of the option grants held by a given individual on a particular date. Then the asymptotic covariance matrix of $\widehat{\beta}$ takes the "sandwich" form (see Gouriéroux et al. (1984)),

$$
\operatorname{var}(\widehat{\beta})=\widehat{\mathbf{A}}^{-1} \widehat{\mathbf{B}} \widehat{\mathbf{A}}^{-1}
$$

where

$$
\begin{aligned}
\widehat{\mathbf{A}} & =\sum_{i, j, t} \frac{\partial^{2} l_{i j t}(\widehat{\beta})}{\partial \beta \partial \beta^{\prime}} \\
& =\sum_{i, j, t} \widehat{g}_{i j t} X_{i j t} X_{i j t}^{\prime}
\end{aligned}
$$


and

$$
\widehat{\mathbf{B}}=\mathbf{X}^{\prime} \widehat{\Omega} \mathbf{X}
$$

where $\mathbf{X}$ is a matrix containing all of the stacked $X_{i j t}$ values, and $\widehat{\Omega}$ is a consistent estimator of $\Omega$ given by

$$
\widehat{\Omega}=\left(\begin{array}{ccccc}
\widehat{\Sigma}_{1} & & \ldots & & 0 \\
& \ddots & & & \\
\vdots & & \widehat{\Sigma}_{i} & & \vdots \\
& & & \ddots & \\
0 & & \ldots & & \widehat{\Sigma}_{I}
\end{array}\right)
$$

where

$$
\widehat{\Sigma}_{i}=\widehat{u}_{i} \widehat{u}_{i}^{\prime}
$$

This covariance matrix is robust both to arbitrary heteroskedasticity and to arbitrary correlation between the residuals in a given block. ${ }^{4}$

\section{Data}

As discussed above, our estimation strategy is carried out using a proprietary data set comprising complete histories of employee stock option grants, vesting structures, and option exercise and cancellation events for all employees who received options at 87 publicly traded corporations between 1983 and 2007. ${ }^{5}$ As shown in Table 1, there is considerable heterogeneity in the sample of firms both in terms of their industry type (reported at one-digit Standard Industrial Classification (SIC) codes) and in terms of the firm sizes measured by market cap and numbers of employees. The largest firms in terms of both market capitalization and numbers of employees are in the financial services sector (SIC 6) and the transportation and communications sector (SIC 4). There are also significant differences in revenue growth rates across sectors. Firms in construction and heavy manufacturing, SIC 1 and 2, delivered the highest revenue growth rate of about $75 \%$ in our sample. The lowest revenue growth rate over the period was in the financial services, insurance and real estate sector, SIC 6. The high-tech computer sector of manufacturing, SIC 3, firms in the sample appear to have been significantly affected by the dot.com bust of 2001 and 2002 compared to the construction and heavy manufacturing sector. All the sectors generated positive revenue grow rates and

\footnotetext{
${ }^{4}$ For further discussion of calculating standard errors in the presence of clustering, see Rogers (1993), Baum, Schaffer, and Stillman (2003), Wooldridge (2003) and Petersen (2008).

${ }^{5}$ The data were obtained as part of a research grant written by the authors and funded by the Society of Actuaries. In addition, we thank Terrence Adamson at AON Consulting who also provided data for this study.
} 
several of these growth rates were substantial such as the transportation, communications and utilities, SIC 4, that generated about a 53\% revenue growth rate. The service sector revenue growth rates were lower for the non-healthcare services (SIC 7) firms which are smaller firms both in terms of numbers of employees and market capitalization rate and higher for the healthcare firms in SIC 8.

Our unit of analysis is an employee-grant-day. For each option grant we merge the appropriate path of daily split-adjusted stock prices and dividends, starting at the initial grant date, to the path of outstanding option vesting and exercise events for all grants and employees. These daily paths are constructed using detailed information on the contractual option vesting structure, the exercise events, and the cancellation events recorded for each grant. We track the employee-grant-days and a series of time-varying covariates until the options in the grant are fully exercised, the options are cancelled, or we reach the end of the sample period of December 30, 2007.

There is significant heterogeneity in the contractual structure of the option grants both across and within firms in our sample. In Table 2, we report the summary statistics for the number of grants per employee over the sample period. To preserve the anonymity of the firms, we report the summary statistics by two-digit SIC groupings using the SIC designation for each firm that is reported in CRSP. As shown in the Table 2, there is considerable variability in the numbers of grants per employee across firms. The mean number of grants per employee ranges from 1.61 grants for firms in the Educational Services sector (SIC 82) to 5.11 grants per employee in the building construction sector. There is also considerable variability within sectors where the number of grants per employee ranges from one to as many as 73 in the health services sector (SIC 80) and 64 in the Chemicals and allied products sector (SIC 28). For the firms, where we have the employee ranking of the employee, the largest grant recipients are typically the CEO or senior managers.

Another feature of the option granting structure is the number of options that are associated with each grant. As shown in Table 3, there is again considerable variability both across industry sectors and within firms. The number of options have been multiplied by the ratio of the firms stock price to the global average stock price so that summary statistics control for the effect of relatively valuable options where the grants are small and large grants when the stock price is relatively low compared to the sample average. As shown, the mean standardized grant sizes are largest in the health services (SIC 80), industrial machinery and computers sector (SIC 35), rubber and plastic products (SIC 30), and amusement and recreation services (SIC 79). The range of the standardized option grant sizes is also large. For example, in the industrial machinery and computes (SIC 35) the number of options per grant ranges from 1.0 to more than one hundred and two million standardized and split- 
adjusted options in a single grant. As shown, many of the option grants across industries involved large numbers of options and these single grant option positions frequently involved millions of options for the senior managers and CEO of these firms. The combined effects of the large number of grants per employee and the size of these grants implies that individual employees are likely to hold large inventories of options with different strikes and vesting structures. This feature of the data introduces significant correlation across the exercise decisions of individual employees. As discussed above, the exercise decision for one option in a given grant held by an individual is highly correlated with the exercise of another option in the same grant held by the same individual. In addition, there would be correlation in the exercise decisions across grants that are held by the same individual. A particular strength of our fractional logistic estimator is that it does not require assumptions of independence across exercise events. We also pool by employee and correct our standard errors to account for our pooled structure.

Table 4 provides summary statistics for the maximum number of contractual vesting dates required before the options in a given grant fully vest. The means range between one vesting date for the petroleum, refining and related sector (SIC 29) and 14.9 for firms in the electronic and other electrical sector (SIC 36). Here again, the range of vesting structures across firms within a sector are very important. An example of a vesting structure that would lead to a large maximum would be a grant with a $25 \%$ vest at the end of the first year and then $2.08 \%$ monthly vests over the next 36 months. The minima are generated by what are termed "cliff vests" where all the options in a given grant vest on the same day. Another feature of the grants that exhibits important heterogeneity across firms is the percentage of options that vest on the first vesting dates. As shown in Table 5, the range of the mean percentage of options that vest on the first vesting date is between $20 \%$ to $100 \%$ across the SIC defined sectors. The within sector variance is also important and the percentage of the grants that vest on the first vesting date ranges between 1\% to 100\%. An 100\% vest is also associated with the common "cliff vest" structure and these vests can occur within one month of issuance.

The summary statistics for the overall time that it takes to fully vest the grants are reported in Table 6. As shown, the mean number of months required for the grants to fully vest is between 7.97 months in the communications sector (SIC 48) and 59.99 months in the educational services sector (SIC 82). The within sector variation is between zero, in which case the grant fully vests on the first grant date, to a maximum of 121 months in the communications sector (SIC 48). The only homogeneous contractual feature of employee stock option grants across firms is the maturity in months from the issuance date to the date of expiry. As shown in Table 7, the term of executive stock options is quite uniformly ten 
years although there are some twenty-year and one-year maturity options granted on the part of some firms. At the employee-level, the employees in our sample are in some cases managing as many as ten different contractual option vesting structures in their inventory of options.

The vesting structure also affects the observed patterns of exercise events. Table 8 presents the summary statistics for the remaining term on the option at the time the option is exercised. Since on average the options in our sample have terms of ten years, these high mean values imply that on average the options in our sample are exercised when there is nearly two-thirds of the option term remaining. These patterns are consistent with those documented by Huddart and Lang (1996). The only sector that does not exhibit this persistent early exercise behavior on the part of employees is fabricated metal products (SIC 34) and communications (SIC 48). The summary statistics reported in Table 9 suggest that on average the options are exercised close to the vesting dates, controlling for the number of days in the interval that the option was in-the-money. The chemicals and allied products firms (SIC 28), petroleum refining and related (SIC 29), and communications (SIC 48) sectors, however, appear to be exceptions to this pattern with mean times between the prior vesting date and the exercise date of 1,069.8, 1057.6, and 2865.3 days respectively.

Table 10 reports the summary statistics for the ratio of the stock price to the exercise price on the option. Not at all surprisingly, these ratios are all greater than one, but again there is very important variation in the ratios both across and within sectors. The very high ratios reflect the run-up in the stock market during our sample period. Overall, both the vesting structure and the option exercise patterns lead to the persistence of early exercise behavior in some industrial sectors but with considerable heterogeneity both within and across the sectors.

Another characteristic that we document in these data is the importance of fractional exercise behavior. As shown in Table 11, the mean percentage of vested options in a grant that are exercised is significantly less than one across all the industry sectors. The means range from about $31.37 \%$ in the engineering, accounting, and management services sector (SIC 87) to a high of about $90.63 \%$ in the petroleum refining and related sector (SIC 29). There is also consider heterogeneity within firms in the industry sectors. Thus, on average employees typically exercise substantially less than $100 \%$ of the outstanding vested options of a grant even though all the vested options in the grant would also be in-the-money. It is this central feature of option exercise behavior that motivates the development of our fractional logistic estimation strategy.

In summary, there are three features of the stock option exercise patterns observed in our sample of 1,475,492 option grants and 873,924 option exercises. First, many employees hold 
more than one option grant and make exercise decisions over more than one vested option at any given time. For this reason, estimation strategies must account for the correlated decision structure of employee option exercise. Second, both the contractual vesting structure and the exogenous price paths appear to have strong effects on option exercise patterns, thus careful controls for both of these feature on a daily basis must be included in a successful estimation strategy. Finally, most option positions are exercised fractionally, that is the proportion of the outstanding options that are exercised at exercise events is, on average, substantially less than one. For this reason, a successful econometric methodology must account for path dependent fractional exercise behavior or risk introducing significant misspecification bias and inaccurate forecasts of exercise timing.

\subsection{The covariates}

As discussed at length in our companion paper, Carpenter et al. (2009), since employee stock options are non-transferable, the optimal exercise policy for these options can look quite different from that for standard American call options. The intuition that the need for diversification can lead an employee to sacrifice some option value by exercising early is well understood in the theoretical literature. However, an explicit theory of the optimal exercise of executive stock options that could be taken directly to data is still developing. Formal theory of the optimal exercise of multiple executive stock option grants is even less developed, although intuition suggests that the greater the option holder's total forced exposure to the stock risk, the greater the exercise rate. Despite the potential limitations of prior theoretical research, we consider two types of path-dependent covariates in our empirical specification of fractional exercise timing. We use both fundamental state variables that have appeared in prior theoretical analyses of optimal stock option exercise policies as well as "behavioral" variables that have been identified in recent empirical options exercise studies (See Huddart and Lang (1996); Heath et al. (1999); Huddart and Lang (2003); Malmendier and Tate (2005); and Armstrong et al. (2006)).

Even the most parsimonious theoretical models define the optimal exercise policies of executive stock options in terms of the time series dynamics of the underlying stock price in conjunction with the contractual timing of options' vesting structures and the timing of expirations. Successful development of empirical models of exercise timing require richer theoretical treatments of the exercise function in terms of variables such as the wealth of the option holder, the holdings of other options and restricted stock, the volatility of the underlying stock price, the portion of risk that is hedgeable using other assets, and the

dividend payout structure of the firm. Unfortunately, the theoretical literature that focuses 
on these richer models is not well developed. The broader theoretical framework of Carpenter et al. (2009) allows for a number of empirically testable predictions concerning the average lives of employee stock options, and we draw upon a number of these predictions to motivate the specification choices for our fractional logistic estimator. A first strong result from the model is that the higher the firm's dividend rate the more likely that the employee will exercise, since loss of dividend through option ownership is a cost of the option that could be avoided through exercise. A second prediction is that the higher correlation of the stock's price with the market (the higher beta), the less likely that exercise will occur. In addition we find that, unlike the standard intuition for the exercise of American calls, volatility does not lead to a clean prediction and may lead both to earlier or later exercise in the case of nontransferable stock options. ${ }^{6}$ For this reason, we consider the effect of stock price volatility on the optimal exercise policy as an open empirical question. Standard intuition holds that risk averse employees are likely to exercise later and the cost of their options is higher. Similarly, employees with decreasing absolute risk aversion will exercise later, implying greater option cost, if they have more non-option wealth and this intuition is again supported in Carpenter et al. (2009). This final prediction not only requires information on the stock price paths but also requires proxies for the risk preferences of the employees who hold the options.

In Table 12 we present the summary statistics for the path dependent covariates. The first four rows of the table present the common state variables in theoretical analyses of optimal employee option exercise policies. The price-to-strike ratio is the employee-grantday observation of the ratio of the split-adjusted price of the stock to the split-adjusted strike price on the option. The stock return volatility is the standard deviation of the daily stock returns, as reported in CRSP, over the prior thirty trading days from each employee-grantday. The firm beta was estimated for each firm using market and firm data from CRSP and interest rate data from the Federal Reserve Board over a five year interval (in some cases the interval is shorter) and is a constant for each firm. The estimated mean beta is about 1.03 and the standard deviation is about 0.32 over the sample period.

Recent empirical studies of employee stock option exercise report links between behavioral indicators, or "rules of thumb", that employees appear to rely upon in making their option exercise decisions. Armstrong et al. (2006) find a statistically significant association between the timing of vesting events and option exercise. They argue that recent exercise events both mechanically affect an employees' ability to exercise their options and may also serve as a periodic reminder to employees to evaluate the value of their option positions. Heath et al. (1999) and Armstrong et al. (2006) also find a statistically significant positive association

\footnotetext{
${ }^{6}$ Option values increase in volatility in both standard option pricing theory and in the case of executive stock option models with an exogenously specified exercise boundary, such as Cvitanić et al. (2004).
} 
between option exercise and the occurrence of the current stock price exceeding the 90th percentile of the past year's price distribution. They argue that this association is driven by cognitive benchmarks that employees use in their decision rules. Given the importance of these variables in prior studies, we also include them as controls in all of our specifications. Our measure of vesting structure is the variable vesting period within two weeks. It is an indicator variable that is one if the employee-grant-day is within two weeks of a vesting event and zero otherwise. Our cognitive benchmark proxy is the variable price relative to the 90th percentile. It is an indicator variable that is equal to one if the observed stock price is greater than or equal to 90th percentile of the stock price distribution over the prior year of trading and zero otherwise. We report the summary statistics for these variables in the lower panel of Table 12. As shown in the table, about 3.4\% of employee-grant-days are within two weeks of a vesting date, on average, and about $60 \%$ of the employee-grant-days are at prices that exceed the 90th percentile of the past year's price distribution, reflecting the large stock price run-ups in the sample period.

A prior empirical literature has found evidence that older individuals are more risk averse in financial decision making than younger individuals and that females appear to be more risk averse than males in their financial decisions (See Bajtelsmit and Bernasek (2001); Bellante and Green (2004); and Armstrong et al. (2006)). As previously discussed, economic intuition suggests that less risk averse employees are likely to exercise later and consequently the cost of their options is greater. For a subset of firms in our sample, we have information on the age, sex, and salary of the employees. The summary statistics for these variables are reported in Table 13. As shown, the subset of the data that includes salary is quite small. The mean salary is about $\$ 294,000$ (the median about $\$ 175,000$ ) and there is significant range between about $\$ 11,000$ and $\$ 368$ million dollars in annual salary. We have information for a subset of about 203,897 employees and as shown in the table the mean age is about 44 years old. Surprisingly, the youngest option recipient is only seventeen years old and the oldest is 85 years old. In a somewhat smaller subsample (172,523 employees for gender and 350,199 employees for employment status), we have information about the gender and employment status of the employee. In this subsample, $55 \%$ of employees are male. About $1 \%$ of the employees are executives and about $1 \%$ are board members. The manager category, about $14 \%$ of the subsample, includes all employees designated as manager, and the other category includes all administrative personnel, logistics personnel, and engineers among many other categories. Our expectation is that, everything else equal, women and older employees will exercise later and that the larger non-diversifiable wealth positions of executives will lead them to exercise earlier.

In Table 14, we report the rates of option cancellation events per year. These covariates 
are important in the valuation simulations since they add three additional reasons for option terminations and they have potentially important effects on the probability of option exercise. The employee stock options in our sample can be cancelled for five reasons: repricing, death, retirement, and termination from the firm for either voluntary or involuntary reasons, or reason unknown. Since we only observed about 4,000 repricings in the sample we ignored the effects of these events. Cancellations as the result of death, retirement and job termination would be expected to force early option exercise since employees are required to relinquish their option positions within 60 days of any of the three events. Therefore, we drop all exercises within six months prior to any of these events in the estimation of the rate of voluntary exercise. Of the 594,660 employees for whom we have cancellation information, the most common reason was job termination. We also had 3679 retirements and 1990 deaths. Table 14 reports the annual proportion of employees who begin a year holding options and are subject to a cancellation at some time during that year due to a job termination, a death, retirement, or an unknown reason. The job termination rates appear to cyclical from 1983 falling in booms and rising in busts. The overall annual average is $6.3 \%$ job termination rates both voluntary and involuntary over the sample period. The annual retirement rate is about $2 \%$ and the annual death rate is about .5\%. As shown in the last column of Table 14, there are also fairly large number of cancellation events each year for which we were not provided with the reason for the cancellation.

Table 15 we report the annual involuntary and voluntary job termination rates for employees in each of the one-digit SIC sectors. As shown in the table, the rates of job churn in the Services sector (SIC 7 and SIC8) are relatively high over most years. More cyclical job termination rates are evident in the computer sector (SIC3) when the dot.com bust led to significant levels of job churn and for the communications industry (SIC4) in 2004, 2005, and again in 2007 again due to retrenchment in the sector. The lowest overall job termination rates are found in the retail sector (SIC5) and the heavy manufacturing sector (SIC2). These two sectors also appear to be significantly less cyclical over the sample period. The financial services sector (SIC 6) experienced job termination turmoil in the recession of 2003 and early 2000 .

In summary, the covariates used in the fractional logistic specification include the salient state variables related to stock price paths, volatility, and market risk that have been the focus of the recent theoretical literature on employee stock option valuation and cost. In addition, we proxy for factors such as risk aversion and possible cognitive benchmarks using the covariates gender, age, salary, and employment status. We use this rich set of covariates to explore a set of theoretically motivated null hypotheses that have appeared in the recent literature. These nulls include: 1) higher dividend rates should make option exercise more 
likely; 2) more risk aversion should make early option exercise more likely; 3) higher volatility is an empirical question, since theoretically it could lead to either earlier or later exercise in a utility maximizing framework; 4) higher correlation with the market makes earlier exercise less likely; and 5) an employee's optimal exercise policy may involve exercising when the stock price exceeds a critical boundary. We report the results of these tests in the next section of the paper.

\section{Estimation Results}

Table 16 shows the results of applying our procedure to the sample of voluntary option exercises described above. We report our results the baseline model with fixed effects at the one-digit SIC code level. The standard errors are reported in parentheses below the coefficient estimates and the estimator clusters at the level of the individual employee.

As shown in the table, the rate of voluntary option exercise is consistently positively related to the level of the stock price as expected. As previously discussed, Carpenter et al. (2009) argue that unlike the standard intuition for the exercise of American calls, volatility does not lead to a clearly signed prediction on an employee's optimal exercise policy. The results reported in Table 16 indicate that once we introduce controls for industry fixed effects, increased levels of stock return volatility are associated with smaller fractions of options exercised, however, the estimate is not statistically significant at standard levels.

As shown in Table 16, the coefficient estimate on firm beta is negative and statistically significant in specification. ${ }^{7}$ We interpret this result as only weak support of our ex ante expectations concerning the effect of beta on executive stock option exercise.

As reported in Table 16 when the stock price is greater than or equal to the $90^{\text {th }}$ percentile of the trading price distribution in the prior three hundred and sixty trading days, the fraction of options that are exercised is also statistically significant and positive. We also find a statistically significant and positive association between the percentage of options that are exercised and recent vesting events, measured by an indicator of whether the exercise event was within a two week window of the last vesting date. As discussed previously, these results are consistent with the earlier empirical studies of Heath et al. (1999) and Armstrong et al. (2006), who argue that employees may tie their exercise decisions to cognitive benchmarks as a means of reducing monitoring costs. As shown in Table 16 the vesting structure has a positive and statistically significant effect on exercise behavior and employees tend to exercise

\footnotetext{
${ }^{7}$ Part of the problem with the firm beta covariate is that we are currently measuring a fixed beta for each firm. In later versions of this paper, we plan to use annual estimates of firms' betas using CRSP aggregate files
} 
larger fractions of options closer to vesting dates. The exercise of vested options in a grant is also statistically associated with the remaining time on the option. Our results indicate that employees are less likely to exercise large fractions of their outstanding vested options when the remaining time is long suggesting that risk aversion is confounded with the effects of the remaining term on the option grant.

\section{Option Cost to the Firm}

For an individual option, the exercise function describes the expected proportion of each outstanding option grant to be voluntarily exercised at a given time and state, conditional on having survived to that point. If the event that the option is actually exercised is sufficiently independent across option holders with identical exercise functions, conditional on the given time and state, then in a large enough pool of such option holders, the fraction of options exercised voluntarily will exactly equal the exercise function. Similarly, the termination function describes the fraction of options stopped through termination in a diversified pool. We assume that such diversification is possible, or, more generally, that the conditional variance in the number of options actually exercised around the expected value is not a priced risk in the market, so that option valuation proceeds as if perfect diversification were possible.

Given the estimated voluntary exercise rate per period, $G(X \beta)$, and termination rate $\lambda$, the value of the option is given by its expected risk-neutral discounted payoff,

$$
\begin{aligned}
O_{t}= & \mathrm{E}_{t}^{*}\left\{\int_{t \vee t_{v}}^{T} e^{-r(\tau-t)}\left(S_{\tau}-K\right)^{+}\left(G_{\tau}+\lambda\right) e^{-\int_{t}^{\tau}\left(G_{s}+\lambda\right) d s} d \tau\right. \\
& \left.+e^{-r(T-t)} e^{-\int_{t}^{T}\left(G_{s}+\lambda\right) d s}\left(S_{T}-K\right)^{+}\right\}
\end{aligned}
$$

where $t_{v}$ is the vesting date. To understand the intuition for this expression, note that $G+\lambda$ measures the expected fraction of a grant exercising or canceling, measured as a fraction of the options still unexercised one period earlier. To calculate the expected fraction of today's options that exercise or cancel at date $t$, we therefore need to multiply by the proportion of the grant outstanding today that has not exercised prior to $t$, given by

$$
e^{-\int_{t}^{\tau} \hat{G}_{s}+\lambda d s} d \tau
$$

We estimate this value with Monte Carlo simulation, using antithetic variates and importance sampling to increase precision. Tables 17-19 report option values, labeled ESO Value, for a variety of parameterizations. The tables assuming the option holder voluntarily exer- 
cises according to the estimated exercise rate function in Table 16, and in addition terminates employment at a constant rate. For the base case, we set the employee age and termination rate equal to their sample average values. We use SIC 3 as the base case industry and set the firm volatility to $50 \%$, dividend rate to zero, which is representative of a technology firm. We set the firm beta to one, the vesting period to two years, and the option expiration date to ten years.

For comparison, the column labeled Modified Black-Scholes (MBS) gives option value approximated as the probability of vesting times the Black-Scholes value adjusted for dividends, with contractual expiration date replaced by the option's expected term, conditional on vesting. While new methodologies are developing, the FASB accepts this approximation for accounting valuation, and it is used by the vast majority of firms. Like ESO Value, we compute the option's expected life using Monte Carlo simulation assuming the option holder follows the estimated exercise rate function and terminates employment at a constant rate. This expectation is with respect to the true probability measure, so it depends on the true expected return on the stock. We assume the mean stock return is determined by the CAPM, with a $6 \%$ excess expected return on the market.

In theory, the MBS approximation can either understate or overstate the true option value, depending on the exercise policy. To understand why, consider two special cases, and for simplicity assume immediate vesting. First, if the option holder follows the valuemaximizing exercise policy in the presence of dividends, as in standard theory, then the true option value will be greater than the Black-Scholes value to any deterministic expiration date, so it will exceed the MBS approximation. Alternatively, suppose the option is stopped, either through exercise or cancellation, at a purely exogenous rate, independent of the stock price, without regard to whether it is in or out of the money. Then the true option value is the average Black-Scholes value over possible stopping dates, while the MBS approximation is Black-Scholes value to the average stopping date, and since the Black-Scholes value tends to be concave in the option expiration date, the MBS approximation will overstate the true value. The exercise policies followed in practice contain elements of both of these examples.

The left side of Tables 17-19 focuses on the case of at-the-money options at their grant date. The right side considers so-called "underwater" options, two years after grant, vested, but $40 \%$ out of the money. With the steep decline in the stock market in the last year, most firms find that the options they granted to employees before the crash are deeply out of the money. Many firms are offering their employees equal-present-value exchanges of at-the-money options for the old out-of-the-money options, perhaps in an effort to restore performance incentives. The last column of Tables 17-19 shows the exchange ratio. In general, the MBS value overstates option value for the parameterizations considered here. 
The overstatement is even greater for the underwater options than for the at-the-money options.

Table 17 shows the effects of changing firm characteristics. The first panel presents volatility effects. Option value increases much more slowly with volatility than the MBS approximation does, so the overstatement increases significantly with volatility. The second panel shows that option value declines with the dividend rate. The MBS approximation declines even faster so the error declines in algebraic value.

The third panel of Table 17 shows the effect of increasing firm beta. This reduces the exercise rate, perhaps because of increased hedging opportunities, which increases option value. Beta has conflicting effects on option expected life. On one hand, its direct effect on the estimated exercise function is to reduce the exercise rate, which can increase expected life. On the other hand, under the true measure, it increases the mean stock return, which means the exercise function is more likely to be evaluated at higher stock prices, which increases the exercise rate and reduces expected option life. For the parameterization here, the first effect dominates, and the MBS approximation error is relatively constant.

Table 18 considers certain employee and contract effects. The first panel shows how option value varies with the termination rate. A higher termination rate increases the chance of prevesting forfeiture, the chance of post-vesting cancellation, and the rate of suboptimal early exercise, so it reduces option value. It also reduces option life, so the MBS approximation also declines. The increased noise in the exercise policy should in principle increase the MBS overstatement, but here that effect is only slight.

The second panel of Table 18 illustrates the effect of increasing the vesting period. A longer vesting period increases the risk of pre-vesting forfeiture, which reduces option value. Conditional on vesting, the option stopping time has less room to vary, so the difference between the option value and the MBS approximation shrinks.

Table 19 shows how option value varies across industry, and how the MBS approximation varies with the equity premium. The first panel shows the effect of varying the constant term in the estimated exercise function according to the estimated coefficients on industry dummies, that is, the base rate of voluntary exercise for different industries. This does not account for differences in value due to different termination rates, which would also have an effect. The second panel shows the effect of increasing the mean stock return. This has no effect ESO value, given the estimated exercise function. However, it reduces the true expected option life, as it increases the rate at which the option gets in the money, so it reduces the MBS value and approximation error. 


\section{Conclusions}

This paper is the first to perform a complete empirical estimation of employee stock option exercise behavior and option cost to firms. We develop a methodology for estimating option exercise and cancellation rates as a function of the stock price path, time to expiration, and firm and option holder characteristics. Our estimation is based on a fractional logistic approach, and accounts for correlation between exercises by the same executive. Valuation proceeds by using the estimated exercise rate function to describe the option's expected payoff along each stock price path, and then computing the present value of the payoff. The estimation of empirical exercise rates also allows us to test the predictions of theoretical models of option exercise behavior.

We apply our estimation technique to the largest dataset yet analyzed in the literature, consisting of a comprehensive sample of option exercise grant and exercise data for all employees at 87 publicly traded firms from 1980 to 2007. Our results indicate that using standard pricing approximations, such as the adjusted Black-Scholes method suggested by FASB, can lead to significant errors. The proprietary data used in this study were provided by corporate participants in a sponsored research project that was funded by the Society of Actuaries, who hope that the results of our study will eventually be used as the standard set of exercise assumptions to be used in calculating ESO values on firms' income statements. 


\section{References}

Armstrong, C. S., A. D. Jagolinzer, and D. F. Larcker, 2006, Timing of employee stock option exercises and the valuation of stock option expense, Working paper, Stanford University. Bajtelsmit, V., and A. Bernasek, 2001, Risk preferences and the investment decisions of older americans, Working paper, American Association of Retired Persons (Washington, D.C.).

Baum, C. F., M. E. Schaffer, and S. Stillman, 2003, Instrumental variables and GMM: Estimation and testing, Stata Journal 3, 1-31.

Bellante, D., and C. Green, 2004, Relative risk aversion among the elderly, Review of Financial Economics 13, 269-281.

Bettis, J. C., J. M. Bizjak, and M. L. Lemmon, 2005, Exercise behavior, valuation, and the incentive effects of employee stock options, Journal of Financial Economics 76, 445-470.

Carpenter, J. N., 1998, The exercise and valuation of executive stock options, Journal of Financial Economics 48, 127-158.

Carpenter, J. N., R. Stanton, and N. Wallace, 2009, Optimal exercise of executive stock options and implications for firm cost, Working paper, Haas School of Business.

Carr, P., and V. Linetsky, 2000, The valuation of executive stock options in an intensity based framework, European Financial Review 4, 211-230.

Cox, D. R., 1972, Regression models and life tables (with discussion), Journal of the Royal Statistical Society 34, 187-220.

Cvitanić, J., Z. Wiener, and F. Zapatero, 2004, Analytic pricing of executive stock options, Working paper, University of Southern California.

Detemple, J., and S. Sundaresan, 1999, Nontraded asset valuation with portfolio constraints: A binomial approach, Review of Financial Studies 12, 835-872.

Duffie, D., and K. J. Singleton, 1999, Modeling term structures of defaultable bonds, Review of Financial Studies 12, 687-720.

Ferrari, S. L., and F. Cribari-Neto, 2004, Beta regression for modeling rates and proportions, Journal of Applied Statistics 31, 799-815.

Gouriéroux, C., A. Monfort, and A. Trognon, 1984, Pseudo-maximum likelihood methods: Theory, Econometrica 52, 681-700.

Heath, C., S. Huddart, and M. Lang, 1999, Psychological factors and stock option exercise, Quarterly Journal of Economics 114, 601-627.

Huddart, S., 1994, Employee stock options, Journal of Accounting and Economics 18, 207231.

Huddart, S., and M. Lang, 1996, Employee stock option exercises: An empirical analysis, Journal of Accounting and Economics 21, 5-43. 
Huddart, S., and M. Lang, 2003, Information distribution within firms: evidence from stock option exercises, Journal of Accounting and Economics 34, 3-31.

Hull, J., and A. White, 2004, How to value employee stock options, Financial Analysts Journal 60, 114-119.

Ingersoll, J., 2006, The subjective and objective evaluation of incentive stock options, Working paper, Yale University, forthcoming Journal of Business.

Jennergren, L. P., and B. Näslund, 1993, A comment on "Valuation of executive stock options and the FASB proposal", Accounting Review 68, 179-183.

Kalbfleisch, J. D., and R. L. Prentice, 1980, The Statistical Analysis of Failure Time Data (John Wiley, New York).

Klein, D., and E. Maug, 2009, How do executives exercise stock options?, Working paper, Mannheim Finance Working Paper 2209-01.

Leung, T., and R. Sircar, 2009, Accounting for risk aversion, vesting, job termination risk and multiple exercises in valuation of employee stock options, Mathematical Finance 19, 99-128.

Li, D. X., 2001, On default correlation: A copula function approach, Working paper, RiskMetrics Group.

Malmendier, U., and G. Tate, 2005, Does overconfidence affect corporate investment? CEO overconfidence measures revisited, Journal of Finance 11, 649-659.

Mullahy, J., 1990, Regression models and transformations for beta-distributed outcomes, Working paper, Trinity College.

Papke, L. E., and J. M. Wooldridge, 1996, Econometric methods for fractional response variables with an application to 401(k) plan participation rates, Journal of Applied Econometrics 11, 619-632.

Petersen, M. A., 2008, Estimating standard errors in finance panel data sets: Comparing approaches, Working paper, Northwestern University, forthcoming Review of Financial Studies.

Rogers, W., 1993, Regression standard errors in clustered samples, Stata Technical Bulletin 13, pp. 19-23.

Schwartz, E. S., and W. N. Torous, 1989, Prepayment and the valuation of mortgage-backed securities, Journal of Finance 44, 375-392.

Wooldridge, J. M., 2003, Cluster-sample methods in applied econometrics, American Economic Review 93, 133-138. 


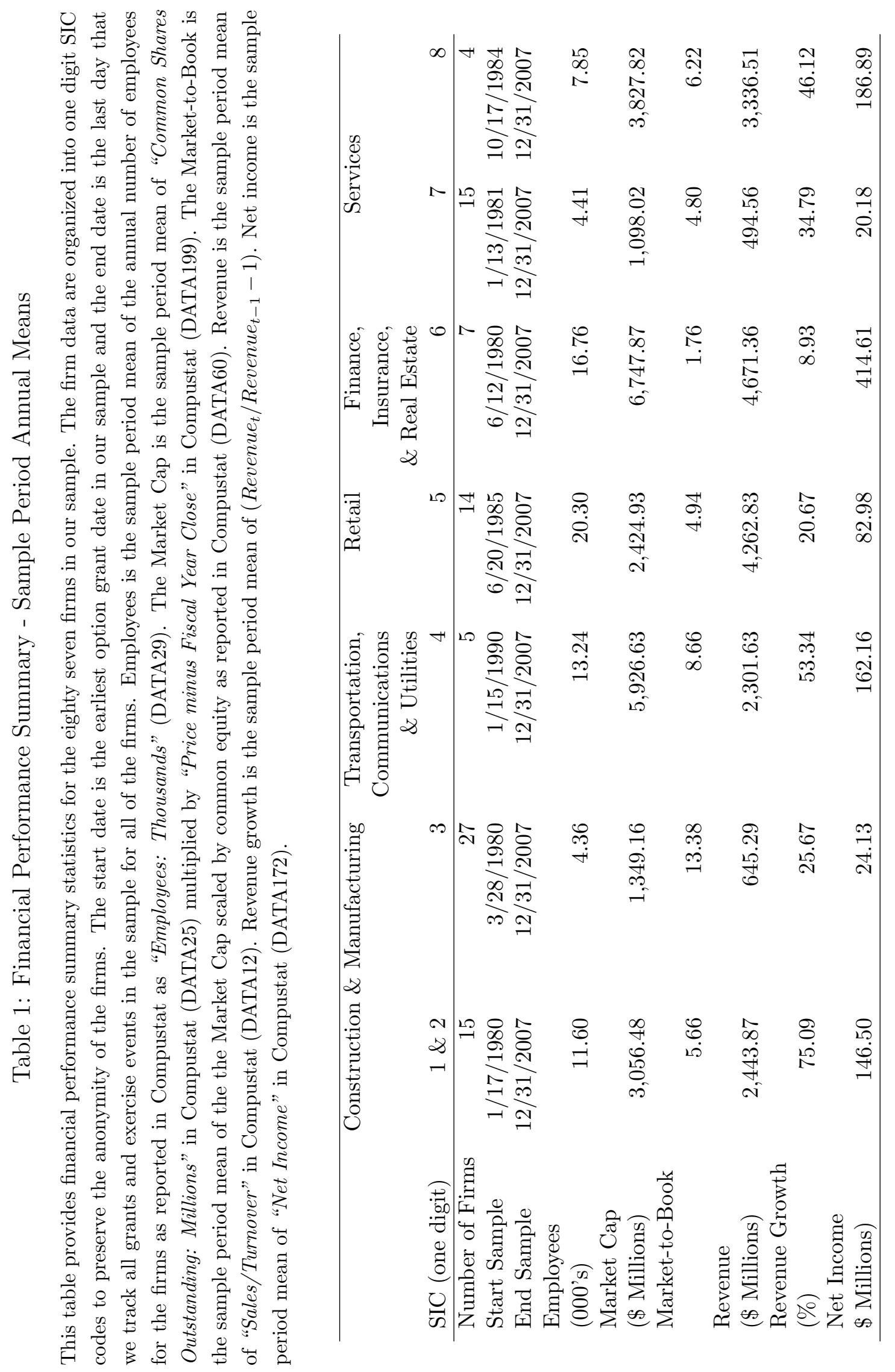


Table 2: Number of Grants Per Employee

This table provides the summary statistics over the sample period for the number of grants that were received by each employee in the eighty seven firms. We organize the summary statistics by the two-digit firm-level SIC categories as reported in CRSP.

\begin{tabular}{|c|c|c|c|c|c|c|}
\hline $\begin{array}{l}\text { SIC } \\
\text { 2-Digit }\end{array}$ & Industry & $\begin{array}{l}\text { Number of } \\
\text { Employees }\end{array}$ & Mean & $\begin{array}{l}\text { Standard } \\
\text { Deviation }\end{array}$ & Minimum & Maximum \\
\hline 15 & Building construction & 1057 & 5.11 & 5.06 & 1.00 & 31.00 \\
\hline 28 & Chemicals and allied products & 202895 & 2.39 & 1.88 & 1.00 & 64.00 \\
\hline 29 & Petroleum refining and related & 166 & 3.11 & 3.06 & 1.00 & 16.00 \\
\hline 30 & Rubber and plastics products & 156 & 2.29 & 2.79 & 1.00 & 18.00 \\
\hline 33 & Primary metal industries & 5498 & 3.60 & 3.50 & 1.00 & 34.00 \\
\hline 34 & Fabricated metal products & 127 & 2.00 & 1.87 & 1.00 & 18.00 \\
\hline 35 & Industrial machinery and computers & 30688 & 2.16 & 1.37 & 1.00 & 34.00 \\
\hline 36 & Electronic and other electrical & 46327 & 3.28 & 4.36 & 1.00 & 39.00 \\
\hline 37 & Transportation equipment & 254 & 3.69 & 2.31 & 1.00 & 10.00 \\
\hline 38 & Measuring, analyzing, controlling instruments & 6784 & 2.34 & 2.19 & 1.00 & 22.00 \\
\hline 39 & Miscellaneous manufacturing & 5600 & 3.13 & 2.53 & 1.00 & 18.00 \\
\hline 48 & Communications & 122180 & 1.82 & 1.45 & 1.00 & 34.00 \\
\hline 49 & Electric, gas, and sanitary services & 1320 & 3.71 & 2.77 & 1.00 & 12.00 \\
\hline 50 & Wholesale trade - Durable goods & 6923 & 1.84 & 1.95 & 1.00 & 18.00 \\
\hline 51 & Wholesale trade - Non-durable goods & 4275 & 4.18 & 3.08 & 1.00 & 16.00 \\
\hline 53 & General merchandise stores & 10111 & 3.72 & 3.39 & 1.00 & 28.00 \\
\hline 57 & Home Furnishing stores & 535 & 2.85 & 2.18 & 1.00 & 10.00 \\
\hline 58 & Eating and drinking places & 3091 & 2.60 & 1.91 & 1.00 & 20.00 \\
\hline 59 & Miscellaneous retail & 14954 & 4.88 & 4.52 & 1.00 & 30.00 \\
\hline 60 & Depository institutions & 59012 & 2.55 & 3.29 & 1.00 & 83.00 \\
\hline 62 & Brokers, dealers, and exchanges & 1823 & 3.62 & 3.24 & 1.00 & 27.00 \\
\hline 63 & Insurance carriers & 8974 & 2.29 & 1.65 & 1.00 & 17.00 \\
\hline 67 & Other investment offices & 748 & 3.36 & 2.48 & 1.00 & 12.00 \\
\hline 73 & Business services & 42339 & 2.49 & 2.91 & 1.00 & 48.00 \\
\hline 79 & Amusement and recreation services & 504 & 2.76 & 2.04 & 1.00 & 14.00 \\
\hline 80 & Health services & 14850 & 3.19 & 3.26 & 1.00 & 73.00 \\
\hline 82 & Educational services & 2614 & 1.61 & 1.65 & 1.00 & 26.00 \\
\hline 87 & Engineering, accounting, management ser. & 855 & 4.78 & 3.14 & 1.00 & 14.00 \\
\hline
\end{tabular}




\section{Table 3: Number of Options Per Grant}

This table reports the number of options per grant at issuance. We multiply the total number of shares granted times the ratio of the price of the stock at the date of issuance to the sample average stock price at the date of issuance $\left(S_{i} / \bar{S}\right)$, where $(\bar{S})$ is the global average stock price over all the firms in the sample. The summary statistics are computed over all grants in the sample period. We organize the summary statistics by the two-digit firm-level SIC categories as reported in CRSP.

\begin{tabular}{|c|c|c|c|c|c|c|}
\hline $\begin{array}{l}\text { SIC } \\
\text { 2-Digit }\end{array}$ & Industry & $\begin{array}{l}\text { Number } \\
\text { of Grants }\end{array}$ & Mean & $\begin{array}{l}\text { Standard } \\
\text { Deviation }\end{array}$ & Minimum & Maximum \\
\hline 15 & Building construction & 5396 & $38,169.5$ & $202,464.9$ & 64.0 & $8,000,000.0$ \\
\hline 28 & Chemicals and allied products & 485518 & $1,310.9$ & $15,862.8$ & 1.0 & $6,400,000.0$ \\
\hline 29 & Petroleum refining and related & 516 & $4,369.3$ & $6,358.0$ & 120.0 & $50,625.0$ \\
\hline 30 & Rubber and plastics products & 358 & $47,570.1$ & $116,767.2$ & 400.0 & $1,600,000.0$ \\
\hline 33 & Primary metal industries & 19814 & $15,015.3$ & $104,304.1$ & 1.0 & $6,593,760.0$ \\
\hline 34 & Fabricated metal products & 254 & $7,295.5$ & $9,520.1$ & 100.0 & $55,403.0$ \\
\hline 35 & Industrial machinery and computers & 66228 & $93,710.4$ & $1,457,224.5$ & 1.0 & $102,400,000.0$ \\
\hline 36 & Electronic and other electrical & 152150 & $3,349.2$ & $31,146.5$ & 1.0 & $6,081,664.0$ \\
\hline 37 & Transportation equipment & 937 & $14,443.3$ & $30,210.7$ & $1,000.0$ & $405,000.0$ \\
\hline 38 & Measuring, analyzing, controlling instruments & 15865 & $5,365.6$ & $22,296.6$ & 1.0 & $900,000.0$ \\
\hline 39 & Miscellaneous manufacturing & 17549 & $7,295.5$ & $55,555.5$ & 50.0 & $4,452,843.8$ \\
\hline 48 & Communications & 221884 & 751.4 & $10,830.6$ & 1.0 & $2,247,030.0$ \\
\hline 49 & Electric, gas, and sanitary services & 4903 & $5,715.2$ & $17,613.8$ & 58.0 & $800,000.0$ \\
\hline 50 & Wholesale trade - Durable goods & 12763 & $1,681.8$ & $16,616.2$ & 40.0 & $1,000,000.0$ \\
\hline 51 & Wholesale trade - Non-durable goods & 17871 & $9,087.1$ & $40,751.9$ & 50.0 & $3,000,000.0$ \\
\hline 53 & General merchandise stores & 37599 & $10,326.8$ & $51,088.0$ & 4.0 & $5,035,712.0$ \\
\hline 57 & Home Furnishing stores & 1524 & $4,654.5$ & $17,706.1$ & 100.0 & $480,000.0$ \\
\hline 58 & Eating and drinking places & 8041 & $8,771.3$ & $38,847.2$ & 1.0 & $1,017,029.3$ \\
\hline 59 & Miscellaneous retail & 73029 & $15,325.0$ & $381,056.4$ & 1.0 & $77,847,802.7$ \\
\hline 60 & Depository institutions & 141211 & $11,864.4$ & $58,789.0$ & 1.0 & $4,857,486.3$ \\
\hline 62 & Brokers, dealers, and exchanges & 6602 & $6,401.8$ & $16,453.2$ & 300.0 & $425,250.0$ \\
\hline 63 & Insurance carriers & 20575 & $3,070.3$ & $11,275.5$ & 1.0 & $675,000.0$ \\
\hline 67 & Other investment offices & 2512 & $4,515.8$ & $11,090.5$ & 23.0 & $234,058.0$ \\
\hline 73 & Business services & 105248 & $7,984.9$ & $52,519.1$ & 1.0 & $4,374,000.0$ \\
\hline 79 & Amusement and recreation services & 1393 & $43,909.4$ & $122,623.7$ & $1,000.0$ & $1,600,000.0$ \\
\hline 80 & Health services & 47445 & $99,410.2$ & $830,404.9$ & 8.0 & $76,800,000.0$ \\
\hline 82 & Educational services & 4221 & 902.0 & $4,081.6$ & 5.0 & $100,000.0$ \\
\hline 87 & Engineering, accounting, management ser. & 4086 & $3,035.8$ & $12,484.5$ & 50.0 & $444,900.0$ \\
\hline
\end{tabular}


Table 4: Maximum Number of Vesting Periods per Grant

This table reports the maximum number of vesting periods required to fully vest a given option grant. The summary statistics are computed over all grants in the sample period. We organize the summary statistics by the two-digit firm-level SIC categories as reported in CRSP.

\begin{tabular}{|c|c|c|c|c|c|c|}
\hline $\begin{array}{l}\text { SIC } \\
\text { 2-Digit }\end{array}$ & Industry & $\begin{array}{l}\text { Number } \\
\text { of Grants }\end{array}$ & Mean & $\begin{array}{l}\text { Standard } \\
\text { Deviation }\end{array}$ & Minimum & Maximum \\
\hline 15 & Building construction & 5396 & 3.62 & 0.87 & 1.00 & 4.00 \\
\hline 28 & Chemicals and allied products & 485518 & 2.52 & 6.01 & 1.00 & 43.00 \\
\hline 29 & Petroleum refining and related & 516 & 1.00 & 0.00 & 1.00 & 1.00 \\
\hline 30 & Rubber and plastics products & 358 & 3.05 & 0.21 & 3.00 & 4.00 \\
\hline 33 & Primary metal industries & 19814 & 3.58 & 1.04 & 1.00 & 4.00 \\
\hline 34 & Fabricated metal products & 254 & 2.19 & 1.89 & 1.00 & 6.00 \\
\hline 35 & Industrial machinery and computers & 66228 & 3.97 & 0.65 & 2.00 & 6.00 \\
\hline 36 & Electronic and other electrical & 152150 & 14.90 & 12.55 & 1.00 & 49.00 \\
\hline 37 & Transportation equipment & 937 & 2.91 & 0.42 & 1.00 & 3.00 \\
\hline 38 & Measuring, analyzing, controlling instruments & 15865 & 8.83 & 13.77 & 1.00 & 48.00 \\
\hline 39 & Miscellaneous manufacturing & 17549 & 3.41 & 0.49 & 3.00 & 4.00 \\
\hline 48 & Communications & 221884 & 1.12 & 0.55 & 1.00 & 4.00 \\
\hline 49 & Electric, gas, and sanitary services & 4903 & 3.65 & 0.48 & 3.00 & 4.00 \\
\hline 50 & Wholesale trade - Durable goods & 12763 & 1.15 & 0.52 & 1.00 & 3.00 \\
\hline 51 & Wholesale trade - Non-durable goods & 17871 & 2.44 & 1.22 & 1.00 & 5.00 \\
\hline 53 & General merchandise stores & 37599 & 4.78 & 0.42 & 3.00 & 7.00 \\
\hline 57 & Home Furnishing stores & 1524 & 2.97 & 0.27 & 1.00 & 4.00 \\
\hline 58 & Eating and drinking places & 8041 & 3.51 & 1.88 & 1.00 & 5.00 \\
\hline 59 & Miscellaneous retail & 73029 & 3.35 & 1.32 & 1.00 & 34.00 \\
\hline 60 & Depository institutions & 141211 & 2.35 & 1.19 & 1.00 & 8.00 \\
\hline 62 & Brokers, dealers, and exchanges & 6602 & 3.00 & 0.12 & 1.00 & 8.00 \\
\hline 63 & Insurance carriers & 20575 & 3.45 & 0.60 & 1.00 & 10.00 \\
\hline 67 & Other investment offices & 2512 & 3.00 & 0.00 & 3.00 & 3.00 \\
\hline 73 & Business services & 105248 & 4.59 & 7.20 & 1.00 & 49.00 \\
\hline 79 & Amusement and recreation services & 1393 & 3.86 & 0.63 & 1.00 & 4.00 \\
\hline 80 & Health services & 47445 & 4.00 & 0.00 & 4.00 & 4.00 \\
\hline 82 & Educational services & 4221 & 5.00 & 0.00 & 5.00 & 5.00 \\
\hline 87 & Engineering, accounting, management ser. & 4086 & 3.00 & 0.00 & 3.00 & 3.00 \\
\hline
\end{tabular}




\section{Table 5: Percentage of the Options that Vest on the First Vesting Date}

This table reports the percentage of the option grants that vest on the first vesting date. The summary statistics are computed over all grants in the sample period. We organize the summary statistics by the two-digit firm-level SIC categories as reported in CRSP.

\begin{tabular}{|c|c|c|c|c|c|c|}
\hline $\begin{array}{l}\text { SIC } \\
\text { 2-Digit }\end{array}$ & Industry & $\begin{array}{l}\text { Number } \\
\text { of Grants }\end{array}$ & Mean & $\begin{array}{r}\text { Standard } \\
\text { Deviation } \\
\%\end{array}$ & Minimum & Maximum \\
\hline 15 & Building construction & 5396 & 31.49 & 17.18 & 25.00 & 100.00 \\
\hline 28 & Chemicals and allied products & 485527 & 85.52 & 30.43 & 2.78 & 100.00 \\
\hline 29 & Petroleum refining and related & 516 & 100.00 & 0.00 & 100.00 & 100.00 \\
\hline 30 & Rubber and plastics products & 358 & 32.94 & 1.77 & 25.00 & 33.33 \\
\hline 33 & Primary metal industries & 19814 & 35.54 & 26.06 & 25.00 & 100.00 \\
\hline 34 & Fabricated metal products & 254 & 74.80 & 35.92 & 16.67 & 100.00 \\
\hline 35 & Industrial machinery and computers & 66228 & 26.13 & 6.21 & 16.67 & 50.00 \\
\hline 36 & Electronic and other electrical & 152362 & 21.14 & 19.41 & 2.08 & 100.00 \\
\hline 37 & Transportation equipment & 937 & 36.39 & 13.96 & 33.33 & 100.00 \\
\hline 38 & Measuring, analyzing, controlling instruments & 15865 & 27.37 & 22.00 & 2.08 & 100.00 \\
\hline 39 & Miscellaneous manufacturing & 17549 & 29.95 & 4.09 & 25.00 & 33.33 \\
\hline 48 & Communications & 221884 & 97.11 & 13.10 & 1.15 & 100.00 \\
\hline 49 & Electric, gas, and sanitary services & 4903 & 27.95 & 3.97 & 25.00 & 33.30 \\
\hline 50 & Wholesale trade - Durable goods & 12763 & 95.11 & 17.38 & 33.33 & 100.00 \\
\hline 51 & Wholesale trade - Non-durable goods & 17871 & 44.83 & 33.37 & 20.00 & 100.00 \\
\hline 53 & General merchandise stores & 37599 & 21.12 & 2.10 & 14.29 & 33.33 \\
\hline 57 & Home Furnishing stores & 1524 & 36.16 & 9.09 & 25.00 & 100.00 \\
\hline 58 & Eating and drinking places & 8041 & 48.85 & 38.09 & 20.00 & 100.00 \\
\hline 59 & Miscellaneous retail & 73900 & 31.69 & 8.05 & 12.50 & 100.00 \\
\hline 60 & Depository institutions & 141363 & 63.84 & 30.88 & 12.50 & 100.00 \\
\hline 62 & Brokers, dealers, and exchanges & 6602 & 59.81 & 2.44 & 25.00 & 100.00 \\
\hline 63 & Insurance carriers & 20575 & 29.82 & 5.18 & 10.00 & 100.00 \\
\hline 67 & Other investment offices & 2512 & 33.33 & 0.00 & 33.33 & 33.33 \\
\hline 73 & Business services & 105249 & 48.33 & 32.20 & 2.08 & 100.00 \\
\hline 79 & Amusement and recreation services & 1393 & 28.50 & 15.82 & 25.00 & 100.00 \\
\hline 80 & Health services & 47913 & 25.00 & 0.00 & 25.00 & 25.00 \\
\hline 82 & Educational services & 4221 & 20.00 & 0.00 & 20.00 & 20.00 \\
\hline 87 & Engineering, accounting, management ser. & 4086 & 33.33 & 0.00 & 33.33 & 33.33 \\
\hline
\end{tabular}


Table 6: Vesting Time (in Months) of the Options

This table reports the total time required to fully vest an option grant. Time is measured in months from the date of issuance to the month at which the grant is fully vested. The summary statistics are computed over all grants in the sample period. We organize the summary statistics by the two-digit firm-level SIC categories as reported in CRSP.

\begin{tabular}{|c|c|c|c|c|c|c|}
\hline $\begin{array}{l}\text { SIC } \\
\text { 2-Digit }\end{array}$ & Industry & $\begin{array}{l}\text { Number } \\
\text { of Grants }\end{array}$ & Mean & $\begin{array}{l}\text { Standard } \\
\text { Deviation }\end{array}$ & Minimum & Maximum \\
\hline 15 & Building construction & 5396 & 43.28 & 10.99 & 0.00 & 48.00 \\
\hline 28 & Chemicals and allied products & 485527 & 22.77 & 17.20 & 0.00 & 120.00 \\
\hline 29 & Petroleum refining and related & 516 & 12.00 & 0.00 & 12.00 & 12.00 \\
\hline 30 & Rubber and plastics products & 358 & 36.38 & 2.92 & 25.00 & 48.00 \\
\hline 33 & Primary metal industries & 19814 & 38.48 & 14.39 & 0.00 & 48.00 \\
\hline 34 & Fabricated metal products & 254 & 54.59 & 15.98 & 0.00 & 72.00 \\
\hline 35 & Industrial machinery and computers & 66228 & 47.63 & 8.19 & 12.00 & 72.00 \\
\hline 36 & Electronic and other electrical & 152362 & 55.52 & 24.44 & 0.00 & 84.00 \\
\hline 37 & Transportation equipment & 937 & 34.79 & 5.52 & 0.00 & 36.00 \\
\hline 38 & Measuring, analyzing, controlling instruments & 15865 & 47.41 & 15.73 & 0.00 & 60.00 \\
\hline 39 & Miscellaneous manufacturing & 17549 & 30.17 & 14.73 & 12.00 & 48.00 \\
\hline 48 & Communications & 221884 & 7.97 & 14.35 & 0.00 & 121.00 \\
\hline 49 & Electric, gas, and sanitary services & 4903 & 43.59 & 5.82 & 25.00 & 48.00 \\
\hline 50 & Wholesale trade - Durable goods & 12763 & 35.84 & 2.36 & 0.00 & 36.00 \\
\hline 51 & Wholesale trade - Non-durable goods & 17871 & 15.02 & 15.37 & 0.00 & 48.00 \\
\hline 53 & General merchandise stores & 37599 & 57.43 & 5.70 & 36.00 & 108.00 \\
\hline 57 & Home Furnishing stores & 1524 & 35.35 & 4.87 & 0.00 & 48.00 \\
\hline 58 & Eating and drinking places & 8041 & 48.79 & 14.94 & 0.00 & 60.00 \\
\hline 59 & Miscellaneous retail & 73900 & 42.48 & 17.07 & 0.00 & 72.00 \\
\hline 60 & Depository institutions & 141363 & 24.35 & 20.07 & 0.00 & 111.00 \\
\hline 62 & Brokers, dealers, and exchanges & 6602 & 35.98 & 0.96 & 1.00 & 48.00 \\
\hline 63 & Insurance carriers & 20575 & 41.34 & 7.28 & 0.00 & 120.00 \\
\hline 67 & Other investment offices & 2512 & 35.99 & 0.36 & 26.00 & 36.00 \\
\hline 73 & Business services & 105249 & 35.60 & 15.95 & 0.00 & 108.00 \\
\hline 79 & Amusement and recreation services & 1393 & 45.76 & 9.99 & 0.00 & 48.00 \\
\hline 80 & Health services & 47913 & 47.94 & 0.73 & 36.00 & 48.00 \\
\hline 82 & Educational services & 4221 & 59.99 & 0.27 & 50.00 & 60.00 \\
\hline 87 & Engineering, accounting, management ser. & 4086 & 36.00 & 0.16 & 26.00 & 36.00 \\
\hline
\end{tabular}


Table 7: Maturity of the Options (in months) at their Issuance Date

This table reports the maturity on option grants at the issuance date. The maturity is measured as the number of months between the issuance date and the expiry date on the grant. The summary statistics are computed over all grants in the sample period. We organize the summary statistics by the two-digit firm-level SIC categories as reported in CRSP.

\begin{tabular}{|c|c|c|c|c|c|c|}
\hline $\begin{array}{l}\text { SIC } \\
\text { 2-Digit }\end{array}$ & Industry & $\begin{array}{l}\text { Number } \\
\text { of Grants }\end{array}$ & Mean & $\begin{array}{l}\text { Standard } \\
\text { Deviation }\end{array}$ & Minimum & Maximum \\
\hline 15 & Building construction & 5396 & 120.00 & 0.00 & 120.00 & 120.00 \\
\hline 28 & Chemicals and allied products & 485518 & 105.09 & 30.51 & 1.00 & 240.00 \\
\hline 29 & Petroleum refining and related & 516 & 120.00 & 0.00 & 120.00 & 120.00 \\
\hline 30 & Rubber and plastics products & 358 & 120.00 & 0.00 & 120.00 & 120.00 \\
\hline 33 & Primary metal industries & 19814 & 120.00 & 0.00 & 120.00 & 120.00 \\
\hline 34 & Fabricated metal products & 254 & 120.00 & 0.00 & 120.00 & 120.00 \\
\hline 35 & Industrial machinery and computers & 66228 & 94.15 & 16.81 & 72.00 & 120.00 \\
\hline 36 & Electronic and other electrical & 152150 & 120.00 & 0.00 & 120.00 & 120.00 \\
\hline 37 & Transportation equipment & 937 & 120.00 & 0.00 & 120.00 & 120.00 \\
\hline 38 & Measuring, analyzing, controlling instruments & 15865 & 120.00 & 0.00 & 120.00 & 120.00 \\
\hline 39 & Miscellaneous manufacturing & 17549 & 120.00 & 0.00 & 120.00 & 120.00 \\
\hline 48 & Communications & 221884 & 91.74 & 40.55 & 3.00 & 240.00 \\
\hline 49 & Electric, gas, and sanitary services & 4903 & 120.00 & 0.00 & 120.00 & 120.00 \\
\hline 50 & Wholesale trade - Durable goods & 12763 & 120.00 & 0.00 & 120.00 & 120.00 \\
\hline 51 & Wholesale trade - Non-durable goods & 17871 & 120.00 & 0.00 & 120.00 & 120.00 \\
\hline 53 & General merchandise stores & 37599 & 130.05 & 22.41 & 120.00 & 180.00 \\
\hline 57 & Home Furnishing stores & 1524 & 120.00 & 0.00 & 120.00 & 120.00 \\
\hline 58 & Eating and drinking places & 8041 & 120.01 & 0.49 & 120.00 & 151.00 \\
\hline 59 & Miscellaneous retail & 73029 & 120.00 & 0.00 & 120.00 & 120.00 \\
\hline 60 & Depository institutions & 141211 & 120.35 & 0.48 & 120.00 & 121.00 \\
\hline 62 & Brokers, dealers, and exchanges & 6602 & 120.00 & 0.00 & 120.00 & 120.00 \\
\hline 63 & Insurance carriers & 20575 & 120.00 & 0.00 & 120.00 & 120.00 \\
\hline 67 & Other investment offices & 2512 & 120.00 & 0.00 & 120.00 & 120.00 \\
\hline 73 & Business services & 101954 & 119.47 & 7.77 & 6.00 & 120.00 \\
\hline 79 & Amusement and recreation services & 1393 & 120.00 & 0.00 & 120.00 & 120.00 \\
\hline 80 & Health services & 47445 & 120.00 & 0.00 & 120.00 & 120.00 \\
\hline 82 & Educational services & 4221 & 120.00 & 0.00 & 120.00 & 120.00 \\
\hline 87 & Engineering, accounting, management ser. & 4086 & 120.00 & 0.00 & 120.00 & 120.00 \\
\hline
\end{tabular}


Table 8: Remaining Term on the Option at the Time of Exercise

This table provides the summary statistics over the sample period for the remaining term (in days) on the option at the date the option is exercised. The remaining term is measured as the difference between the date of expiry and the exercise date. We organize the summary statistics by the two-digit firm-level SIC categories as reported in CRSP.

SIC Industry

2-Digit

$\begin{array}{rrrr}\text { Number of } & \text { Mean } & \begin{array}{r}\text { Standard Minimum Maximum } \\ \text { Deviation }\end{array} & \\ \text { Evercise } & & & \\ \text { Events } & & & \end{array}$

\begin{tabular}{|c|c|c|c|c|c|c|}
\hline 15 & Building construction & 6783 & 2463.28 & 641.26 & 0.00 & 3469.00 \\
\hline 28 & Chemicals and allied products & 304666 & 1652.36 & 1189.19 & 0.00 & 4639.00 \\
\hline 29 & Petroleum refining and related & 441 & 2215.86 & 894.31 & 0.00 & 3283.00 \\
\hline 30 & Rubber and plastics products & 385 & 1989.95 & 966.09 & 1.00 & 3525.00 \\
\hline 33 & Primary metal industries & 13503 & 2553.46 & 634.02 & 0.00 & 3646.00 \\
\hline 34 & Fabricated metal products & 32 & 254.69 & 341.78 & 0.00 & 1081.00 \\
\hline 35 & Industrial machinery and computers & 32538 & 1479.36 & 918.36 & 0.00 & 3616.00 \\
\hline 36 & Electronic and other electrical & 74130 & 2774.71 & 496.21 & 101.00 & 3649.00 \\
\hline 37 & Transportation equipment & 1000 & 2760.48 & 457.88 & 408.00 & 3483.00 \\
\hline 38 & Measuring, analyzing, controlling instruments & 12645 & 2211.45 & 881.85 & 0.00 & 3643.00 \\
\hline 39 & Miscellaneous manufacturing & 7942 & 2673.84 & 678.32 & 0.00 & 3469.00 \\
\hline 48 & Communications & 32057 & 469.70 & 869.62 & 0.00 & 5261.00 \\
\hline 49 & Electric, gas, and sanitary services & 5771 & 2548.85 & 519.43 & 25.00 & 3478.00 \\
\hline 50 & Wholesale trade - Durable goods & 5970 & 2068.94 & 590.10 & 0.00 & 3349.00 \\
\hline 51 & Wholesale trade - Non-durable goods & 6160 & 2495.33 & 630.19 & 307.00 & 3515.00 \\
\hline 53 & General merchandise stores & 34840 & 2257.78 & 1016.00 & 0.00 & 5292.00 \\
\hline 57 & Home Furnishing stores & 471 & 2815.73 & 410.91 & 1598.00 & 3629.00 \\
\hline 58 & Eating and drinking places & 4891 & 1465.18 & 1186.71 & 0.00 & 3429.00 \\
\hline 59 & Miscellaneous retail & 69797 & 2330.87 & 652.46 & 0.00 & 3650.00 \\
\hline 60 & Depository institutions & 100146 & 2294.56 & 774.64 & 0.00 & 3896.00 \\
\hline 62 & Brokers, dealers, and exchanges & 3900 & 1897.79 & 341.32 & 480.00 & 3638.00 \\
\hline 63 & Insurance carriers & 10937 & 2607.62 & 541.60 & 0.00 & 3479.00 \\
\hline 67 & Other investment offices & 645 & 2416.62 & 722.16 & 360.00 & 3425.00 \\
\hline 73 & Business services & 86279 & 2581.08 & 671.23 & 0.00 & 3629.00 \\
\hline 79 & Amusement and recreation services & 1842 & 2645.29 & 474.67 & 420.00 & 3385.00 \\
\hline 80 & Health services & 52085 & 2480.48 & 614.84 & 0.00 & 3545.00 \\
\hline 82 & Educational services & 933 & 2265.49 & 597.72 & 872.00 & 3367.00 \\
\hline 87 & Engineering, accounting, management ser. & 3135 & 1930.18 & 1018.85 & 0.00 & 3368.00 \\
\hline
\end{tabular}


Table 9: Number of Days that the Option was In-the-Money from the Vesting Day to the Exercise Day

This table reports the summary statistics for the number of days that the option was in-the-money from the vesting day on the options to the date of exercise. We sum all days between the vesting date and the exercise date where the ratio of stock price to the strike price is greater than or equal to one. We organize the summary statistics by the two-digit firm-level SIC categories as reported in CRSP.

\begin{tabular}{|c|c|c|c|c|c|c|}
\hline $\begin{array}{l}\text { SIC } \\
\text { 2-Digit }\end{array}$ & Industry & $\begin{array}{r}\text { Number of } \\
\text { Exercise } \\
\text { Events }\end{array}$ & Mean & $\begin{array}{l}\text { Standard } \\
\text { Deviation }\end{array}$ & Minimum & Maximum \\
\hline 15 & Building construction & 6783 & 286.0 & 475.6 & 0.0 & 3586.0 \\
\hline 28 & Chemicals and allied products & 304666 & 1069.8 & 1114.0 & 0.0 & 3665.0 \\
\hline 29 & Petroleum refining and related & 441 & 1057.6 & 921.3 & 0.0 & 3313.0 \\
\hline 30 & Rubber and plastics products & 385 & 736.1 & 810.1 & 0.0 & 2563.0 \\
\hline 33 & Primary metal industries & 13503 & 223.1 & 331.5 & 0.0 & 2212.0 \\
\hline 34 & Fabricated metal products & 32 & 765.6 & 884.4 & 0.0 & 2242.0 \\
\hline 35 & Industrial machinery and computers & 32538 & 297.0 & 365.7 & 0.0 & 2218.0 \\
\hline 36 & Electronic and other electrical & 74130 & 79.1 & 226.7 & 0.0 & 3253.0 \\
\hline 37 & Transportation equipment & 1000 & 88.0 & 205.0 & 0.0 & 2164.0 \\
\hline 38 & Measuring, analyzing, controlling instruments & 12645 & 237.0 & 422.2 & 0.0 & 2929.0 \\
\hline 39 & Miscellaneous manufacturing & 7942 & 190.1 & 407.3 & 0.0 & 2207.0 \\
\hline 48 & Communications & 32057 & 2865.3 & 1270.8 & 0.0 & 3990.0 \\
\hline 49 & Electric, gas, and sanitary services & 5771 & 122.2 & 192.0 & 0.0 & 2004.0 \\
\hline 50 & Wholesale trade - Durable goods & 5970 & 510.4 & 588.7 & 0.0 & 2792.0 \\
\hline 51 & Wholesale trade - Non-durable goods & 6160 & 695.3 & 768.5 & 0.0 & 3208.0 \\
\hline 53 & General merchandise stores & 34840 & 321.1 & 470.1 & 0.0 & 3527.0 \\
\hline 57 & Home Furnishing stores & 471 & 118.6 & 129.7 & 0.0 & 971.0 \\
\hline 58 & Eating and drinking places & 4891 & 315.5 & 420.1 & 0.0 & 3124.0 \\
\hline 59 & Miscellaneous retail & 69797 & 222.6 & 406.6 & 0.0 & 2716.0 \\
\hline 60 & Depository institutions & 100146 & 768.8 & 824.2 & 0.0 & 4667.0 \\
\hline 62 & Brokers, dealers, and exchanges & 3900 & 684.7 & 321.3 & 0.0 & 2631.0 \\
\hline 63 & Insurance carriers & 10937 & 117.5 & 164.7 & 0.0 & 1826.0 \\
\hline 67 & Other investment offices & 645 & 126.0 & 348.0 & 0.0 & 2022.0 \\
\hline 73 & Business services & 86279 & 473.3 & 572.8 & 0.0 & 3676.0 \\
\hline 79 & Amusement and recreation services & 1842 & 147.3 & 249.2 & 0.0 & 2543.0 \\
\hline 80 & Health services & 52085 & 203.6 & 338.6 & 0.0 & 2220.0 \\
\hline 82 & Educational services & 933 & 164.7 & 147.7 & 0.0 & 971.0 \\
\hline 87 & Engineering, accounting, management ser. & 3135 & 344.4 & 674.9 & 0.0 & 2567.0 \\
\hline
\end{tabular}


Table 10: Ratio of the Stock Price to the Strike Price at the Time of Exercise

This table reports summary statistics over the sample period for the ratio of the stock price to the strike price $(S / K)$ on the date the option is exercised. Both the price and the strike are adjusted for splits. We organize the summary statistics by the two-digit firm-level SIC categories as reported in CRSP.

\begin{tabular}{|c|c|c|c|c|c|c|}
\hline $\begin{array}{l}\text { SIC } \\
\text { 2-Digit }\end{array}$ & Industry & $\begin{array}{r}\text { Number of } \\
\text { Exercise } \\
\text { Events }\end{array}$ & Mean & $\begin{array}{l}\text { Standard } \\
\text { Deviation }\end{array}$ & Minimum & Maximum \\
\hline 15 & Building construction & 6783 & 10.08 & 6.59 & 1.92 & 53.26 \\
\hline 28 & Chemicals and allied products & 304666 & 3.38 & 2.40 & 1.00 & 329.63 \\
\hline 29 & Petroleum refining and related & 441 & 1.95 & 0.89 & 1.01 & 9.22 \\
\hline 30 & Rubber and plastics products & 385 & 1.64 & 0.41 & 1.00 & 3.59 \\
\hline 33 & Primary metal industries & 13503 & 4.03 & 2.75 & 1.00 & 23.19 \\
\hline 34 & Fabricated metal products & 32 & 3.19 & 2.41 & 1.03 & 8.76 \\
\hline 35 & Industrial machinery and computers & 32538 & 3.45 & 2.17 & 1.00 & 29.66 \\
\hline 36 & Electronic and other electrical & 74130 & 1.57 & 1.31 & 1.00 & 20.64 \\
\hline 37 & Transportation equipment & 1000 & 4.08 & 2.14 & 1.53 & 21.62 \\
\hline 38 & Measuring, analyzing, controlling instruments & 12645 & 3.30 & 2.09 & 1.00 & 21.51 \\
\hline 39 & Miscellaneous manufacturing & 7942 & 2.07 & 0.82 & 1.00 & 9.82 \\
\hline 48 & Communications & 32057 & 2.03 & 1.58 & 1.00 & 21.76 \\
\hline 49 & Electric, gas, and sanitary services & 5771 & 1.87 & 0.48 & 1.01 & 7.77 \\
\hline 50 & Wholesale trade - Durable goods & 5970 & 1.76 & 0.91 & 1.02 & 13.58 \\
\hline 51 & Wholesale trade - Non-durable goods & 6160 & 4.99 & 3.03 & 1.00 & 18.27 \\
\hline 53 & General merchandise stores & 34840 & 5.91 & 5.28 & 1.00 & 95.65 \\
\hline 57 & Home Furnishing stores & 471 & 2.50 & 1.73 & 1.03 & 13.23 \\
\hline 58 & Eating and drinking places & 4891 & 1.69 & 0.77 & 1.00 & 10.17 \\
\hline 59 & Miscellaneous retail & 69797 & 4.07 & 6.73 & 1.00 & 81.62 \\
\hline 60 & Depository institutions & 100146 & 6.16 & 8.69 & 1.00 & 147.58 \\
\hline 62 & Brokers, dealers, and exchanges & 3900 & 3.22 & 1.23 & 1.16 & 8.73 \\
\hline 63 & Insurance carriers & 10937 & 1.86 & 0.80 & 1.01 & 20.24 \\
\hline 67 & Other investment offices & 645 & 2.06 & 0.41 & 1.08 & 2.84 \\
\hline 73 & Business services & 86279 & 7.03 & 16.01 & 1.00 & 335.10 \\
\hline 79 & Amusement and recreation services & 1842 & 7.18 & 2.38 & 2.61 & 14.14 \\
\hline 80 & Health services & 52085 & 11.48 & 12.14 & 1.00 & 215.26 \\
\hline 82 & Educational services & 933 & 2.04 & 1.17 & 1.01 & 6.60 \\
\hline 87 & Engineering, accounting, management ser. & 3135 & 3.92 & 3.14 & 1.01 & 17.31 \\
\hline
\end{tabular}




\section{Table 11: Percentage of the Grant's Vested Options That Are Exercised}

This table reports the summary statistics for the percentage of each grant's vested options that are exercised on the date of exercise. The percentage is computed as the ratio of the number of options exercised to the total number of number of vested options on the grant that are still unexercised. We then compute the summary statistics using the total vested options outstanding to control for the size of the employee's option position. We organize the summary statistics by the two-digit firm-level SIC categories as reported in CRSP.

\begin{tabular}{|c|c|c|c|c|c|c|}
\hline \multirow[t]{2}{*}{$\begin{array}{l}\text { SIC } \\
\text { 2-Digit }\end{array}$} & \multirow[t]{2}{*}{ Industry } & \multirow[t]{2}{*}{$\begin{array}{r}\text { Number of } \\
\text { Exercise } \\
\text { Events }\end{array}$} & \multirow{2}{*}{$\begin{array}{r}\text { Mean } \\
\\
\%\end{array}$} & \multirow{2}{*}{$\begin{array}{r}\text { Standard } \\
\text { Deviation } \\
\%\end{array}$} & \multirow{2}{*}{$\begin{array}{r}\text { Minimum } \\
\%\end{array}$} & \multirow{2}{*}{$\begin{array}{r}\text { Maximum } \\
\%\end{array}$} \\
\hline & & & & & & \\
\hline 15 & Building construction & 6783 & 72.85 & 26.02 & 100.00 & 0.70 \\
\hline 28 & Chemicals and allied products & 304666 & 70.54 & 32.33 & 100.00 & 0.10 \\
\hline 29 & Petroleum refining and related & 441 & 90.63 & 31.66 & 100.00 & 6.70 \\
\hline 30 & Rubber and plastics products & 385 & 78.75 & 29.41 & 100.00 & 1.70 \\
\hline 33 & Primary metal industries & 13503 & 66.22 & 26.51 & 100.00 & 0.10 \\
\hline 34 & Fabricated metal products & 32 & 64.56 & 29.37 & 100.00 & 6.90 \\
\hline 35 & Industrial machinery and computers & 32538 & 76.96 & 30.40 & 100.00 & 0.10 \\
\hline 36 & Electronic and other electrical & 74130 & 51.18 & 24.91 & 100.00 & 0.10 \\
\hline 37 & Transportation equipment & 1000 & 79.92 & 28.15 & 100.00 & 0.60 \\
\hline 38 & Measuring, analyzing, controlling instruments & 12645 & 65.52 & 24.20 & 100.00 & 0.50 \\
\hline 39 & Miscellaneous manufacturing & 7942 & 56.50 & 25.21 & 100.00 & 0.10 \\
\hline 48 & Communications & 32057 & 78.38 & 31.97 & 100.00 & 1.00 \\
\hline 49 & Electric, gas, and sanitary services & 5771 & 73.66 & 33.27 & 100.00 & 1.20 \\
\hline 50 & Wholesale trade - Durable goods & 5970 & 76.60 & 34.61 & 100.00 & 1.10 \\
\hline 51 & Wholesale trade - Non-durable goods & 6160 & 22.16 & 8.65 & 100.00 & 0.20 \\
\hline 53 & General merchandise stores & 34840 & 53.56 & 24.59 & 100.00 & 0.10 \\
\hline 57 & Home Furnishing stores & 471 & 67.29 & 24.73 & 100.00 & 4.10 \\
\hline 58 & Eating and drinking places & 4891 & 72.57 & 33.10 & 100.00 & 1.30 \\
\hline 59 & Miscellaneous retail & 69797 & 39.85 & 17.36 & 100.00 & 0.10 \\
\hline 60 & Depository institutions & 100146 & 63.30 & 28.59 & 100.00 & 0.10 \\
\hline 62 & Brokers, dealers, and exchanges & 3900 & 79.97 & 28.44 & 100.00 & 3.30 \\
\hline 63 & Insurance carriers & 10937 & 75.29 & 29.07 & 100.00 & 0.10 \\
\hline 67 & Other investment offices & 645 & 69.43 & 28.72 & 100.00 & 0.50 \\
\hline 73 & Business services & 86279 & 61.53 & 28.47 & 100.00 & 0.10 \\
\hline 79 & Amusement and recreation services & 1842 & 75.37 & 28.86 & 100.00 & 7.70 \\
\hline 80 & Health services & 52085 & 60.00 & 23.92 & 100.00 & 0.10 \\
\hline 82 & Educational services & 933 & 88.96 & 30.43 & 100.00 & 6.10 \\
\hline 87 & Engineering, accounting, management ser. & 3135 & 31.37 & 15.64 & 100.00 & 0.00 \\
\hline
\end{tabular}


Table 12: Summary Statistics for the Covariate Paths

This table reports the summary statistics for the employee-grant-day paths for option grants in the sample. The price-to-strike ratio is the daily observation of the ratio of the split-adjusted price of the stock to the split-adjusted strike price on the option (the zero valued minimum is due to our reporting precision). The dividend payment is equal to the split-adjusted dividend payment on each day. This value is zero on all but dividend payment days. The firm beta was estimated for each firm using market and firm data from CRSP and interest rate data from the Federal Reserve Board over a five year interval (in some cases the interval is shorter) and is a constant for each firm. The vesting period within two weeks is an indicator variable that is one if the day is within two weeks of a vesting event and zero otherwise. The stock return volatility is the standard deviation of the daily stock returns, as reported in CRSP, over the past thirty trading days. The price relative to the 90th percentile is an indicator variable that is equal to one if the observed stock price is greater than or equal to 90th percentile of the stock price distribution over the prior year of trading. It is equal to zero otherwise.

Variable

Mean Standard Minimum Maximum Deviation

\begin{tabular}{lrrrr}
\hline Price-to-Strike Ratio & 2.368 & 7.525 & 1.000 & 220.700 \\
Stock return volatility past thirty days & 0.019 & 0.012 & 0.001 & 0.398 \\
Firm Beta & 1.034 & 0.323 & 0.213 & 2.340 \\
Vesting event within two weeks (Indicator variable) & 0.034 & 0.182 & 0 & 1 \\
Price relative to $90^{\text {th }}$ percentile (indicator variable) & 0.596 & 0.491 & 0 & 1 \\
Remaining time (days) & 2480.000 & 714.750 & 181.000 & 5292.000 \\
\hline
\end{tabular}

$\mathrm{n}=701,486,213$

\section{Table 13: Employee Demographics}

This table presents summary statistics for the demographic information that is reported by a subset of the firms in the sample. We summarize the information by employees over the sample period.

\begin{tabular}{lrrrrr}
\hline & $\begin{array}{c}\text { Number } \\
\text { of Employees }\end{array}$ & Mean & $\begin{array}{c}\text { Standard } \\
\text { Deviation }\end{array}$ & Minimum & Maximum \\
\hline Age & 203897 & 43.68 & 12.97 & 17.00 & 85.00 \\
Salary & 54419 & 293871.35 & 358877.38 & 10190.00 & 36835200.00 \\
sex & 172523 & 0.55 & 0.50 & 0.00 & 1.00 \\
Executive & 350199 & 0.01 & 0.12 & 0.00 & 1.00 \\
Managers & 350199 & 0.14 & 0.34 & 0.00 & 1.00 \\
Board member & 350199 & 0.01 & 0.07 & 0.00 & 1.00 \\
\hline
\end{tabular}


Table 14: Cancellation Rates and Reason for Cancellations

This table presents the rates of cancellation events for all firms over the sample period. Only some of the firms reported the reason for cancellations. Of those firms that report the reason for the termination, the category Terminate Position includes all cancellations arising from employment terminations that are either voluntary or involuntary. The other categories that are reported include deaths and retirements. The many of cancellations do not have further information concerning the reason for the cancellation.

\begin{tabular}{|c|c|c|c|c|c|}
\hline year & $\begin{array}{l}\text { Total Employees } \\
\text { Beginning of Year }\end{array}$ & $\begin{array}{r}\text { Cancellation Due to } \\
\text { Voluntary or Involuntary } \\
\text { Termination }\end{array}$ & $\begin{array}{c}\text { Cancellation } \\
\text { Due to Retirement }\end{array}$ & $\begin{array}{l}\text { Cancellation } \\
\text { Due to Death }\end{array}$ & $\begin{array}{l}\text { Cancellation for } \\
\text { Unknown Reason }\end{array}$ \\
\hline 1983 & 206 & 0.0049 & 0.0000 & 0.0000 & 0.0000 \\
\hline 1984 & 269 & 0.0520 & 0.0000 & 0.0000 & 0.0000 \\
\hline 1985 & 665 & 0.0421 & 0.0015 & 0.0000 & 0.0000 \\
\hline 1986 & 1007 & 0.0278 & 0.0050 & 0.0000 & 0.0020 \\
\hline 1987 & 3583 & 0.0070 & 0.0011 & 0.0000 & 0.0000 \\
\hline 1988 & 4396 & 0.0560 & 0.0364 & 0.0000 & 0.0018 \\
\hline 1989 & 5010 & 0.0521 & 0.0321 & 0.0010 & 0.0022 \\
\hline 1990 & 5687 & 0.0570 & 0.0387 & 0.0002 & 0.0039 \\
\hline 1991 & 6710 & 0.0735 & 0.0210 & 0.0001 & 0.0028 \\
\hline 1992 & 134806 & 0.0091 & 0.0017 & 0.0004 & 0.0001 \\
\hline 1993 & 135897 & 0.0188 & 0.0025 & 0.0001 & 0.0001 \\
\hline 1994 & 137524 & 0.0151 & 0.0029 & 0.0001 & 0.0002 \\
\hline 1995 & 132076 & 0.0167 & 0.0064 & 0.0009 & 0.0005 \\
\hline 1996 & 146865 & 0.0212 & 0.0075 & 0.0008 & 0.0003 \\
\hline 1997 & 159927 & 0.0167 & 0.0069 & 0.0005 & 0.0002 \\
\hline 1998 & 221543 & 0.0219 & 0.0066 & 0.0003 & 0.0001 \\
\hline 1999 & 233544 & 0.0317 & 0.0137 & 0.0003 & 0.0001 \\
\hline 2000 & 247536 & 0.0299 & 0.0135 & 0.0002 & 0.0002 \\
\hline 2001 & 309606 & 0.0414 & 0.0226 & 0.0005 & 0.0002 \\
\hline 2002 & 348034 & 0.0597 & 0.0440 & 0.0004 & 0.0019 \\
\hline 2003 & 364742 & 0.0584 & 0.0377 & 0.0004 & 0.0026 \\
\hline 2004 & 381349 & 0.0713 & 0.0410 & 0.0004 & 0.0014 \\
\hline 2005 & 368994 & 0.0830 & 0.0267 & 0.0004 & 0.0012 \\
\hline 2006 & 275908 & 0.0520 & 0.0186 & 0.0006 & 0.0011 \\
\hline 2007 & 257663 & 0.2680 & 0.0046 & 0.0014 & 0.0001 \\
\hline Total & 3349976 & 0.0633 & 0.0187 & 0.0005 & 0.0008 \\
\hline
\end{tabular}


Table 15: Cancellation Rates and Reason for Cancellations by One Digit SIC

This table presents the average rates of cancellation for one digit Standard Industrial Classification (SIS) for all firms over the sample period.

\begin{tabular}{lrrrrrrr}
\hline & Manufacturing & $\begin{array}{r}\text { Transportation, } \\
\text { Communications } \\
\text { \& Utilities }\end{array}$ & Retail & $\begin{array}{r}\text { Finance, } \\
\text { Insurance, } \\
\text { \& Real Estate }\end{array}$ \\
SIC (one digit) & 2 & 3 & 4 & 5 & 6 & 7 & 8 \\
\hline Year & 15 & 27 & 5 & 14 & 7 & 15 & 4 \\
1995 & 0.043 & 0.053 & 0.002 & 0.039 & 0.052 & 0.063 & 0.064 \\
1996 & 0.035 & 0.063 & 0.001 & 0.059 & 0.024 & 0.026 & 0.056 \\
1997 & 0.041 & 0.020 & 0.000 & 0.058 & 0.099 & 0.036 & 0.078 \\
1998 & 0.062 & 0.083 & 0.000 & 0.062 & 0.073 & 0.050 & 0.081 \\
1999 & 0.050 & 0.063 & 0.000 & 0.050 & 0.045 & 0.026 & 0.122 \\
2000 & 0.050 & 0.041 & 0.001 & 0.056 & 0.112 & 0.050 & 0.106 \\
2001 & 0.046 & 0.158 & 0.001 & 0.079 & 0.054 & 0.082 & 0.080 \\
2002 & 0.057 & 0.136 & 0.006 & 0.066 & 0.084 & 0.099 & 0.068 \\
2003 & 0.042 & 0.144 & 0.031 & 0.066 & 0.160 & 0.112 & 0.065 \\
2004 & 0.047 & 0.116 & 0.130 & 0.061 & 0.095 & 0.060 & 0.055 \\
2005 & 0.075 & 0.077 & 0.441 & 0.041 & 0.069 & 0.099 & 0.046 \\
2006 & 0.050 & 0.055 & 0.027 & 0.024 & 0.046 & 0.301 & 0.063 \\
2007 & 0.253 & 0.001 & 0.471 & 0.002 & 0.006 & 0.028 & 0.091 \\
\hline Annual Average & 0.065 & 0.078 & 0.086 & 0.051 & 0.071 & 0.079 & 0.075 \\
\hline
\end{tabular}




\section{Table 16: Estimation Results}

This table presents the results for alternative specifications of the fractional logistic estimator. Specifications 1 and 2 are estimated on the full sample. In specification 1, we exclude both the sex and age covariates and the firm fixed effects. Specification 2 includes firm fixed effects and again excludes the sex and age covariates. Specifications 3 and 4 are estimated with a smaller subsample of firms that reported information on sex and age. Specification 3 includes sex and age and excludes firm fixed effects. Specification 4 includes sex, age and firm fixed effects. The standard errors are reported in parentheses below the coefficient estimates. The estimator clusters at the level of the individual employee.

\begin{tabular}{lr}
\hline Covariates & $\begin{array}{r}\text { Coefficient Estimates } \\
\text { (Standard Errors) }\end{array}$ \\
\hline Constant & -6.009 \\
Price-to-strike ratio & $(0.001)$ \\
Stock return volatility over prior 66 trading days & 0.003 \\
Firm beta & $(0.00003)$ \\
Vesting event in prior 10 trading days (Indicator Variable) & -0.180 \\
& $(0.16)$ \\
Price $\geq 90^{\text {th }}$ percentile of prior year distribution (Indicator Variable) & -0.193 \\
Remaining calendar days until expiration at the time of exercise & $(0.007)$ \\
& 2.356 \\
One-Digit SIC Fixed Effects & $(0.005)$ \\
Number of observations & 0.176 \\
\hline
\end{tabular}




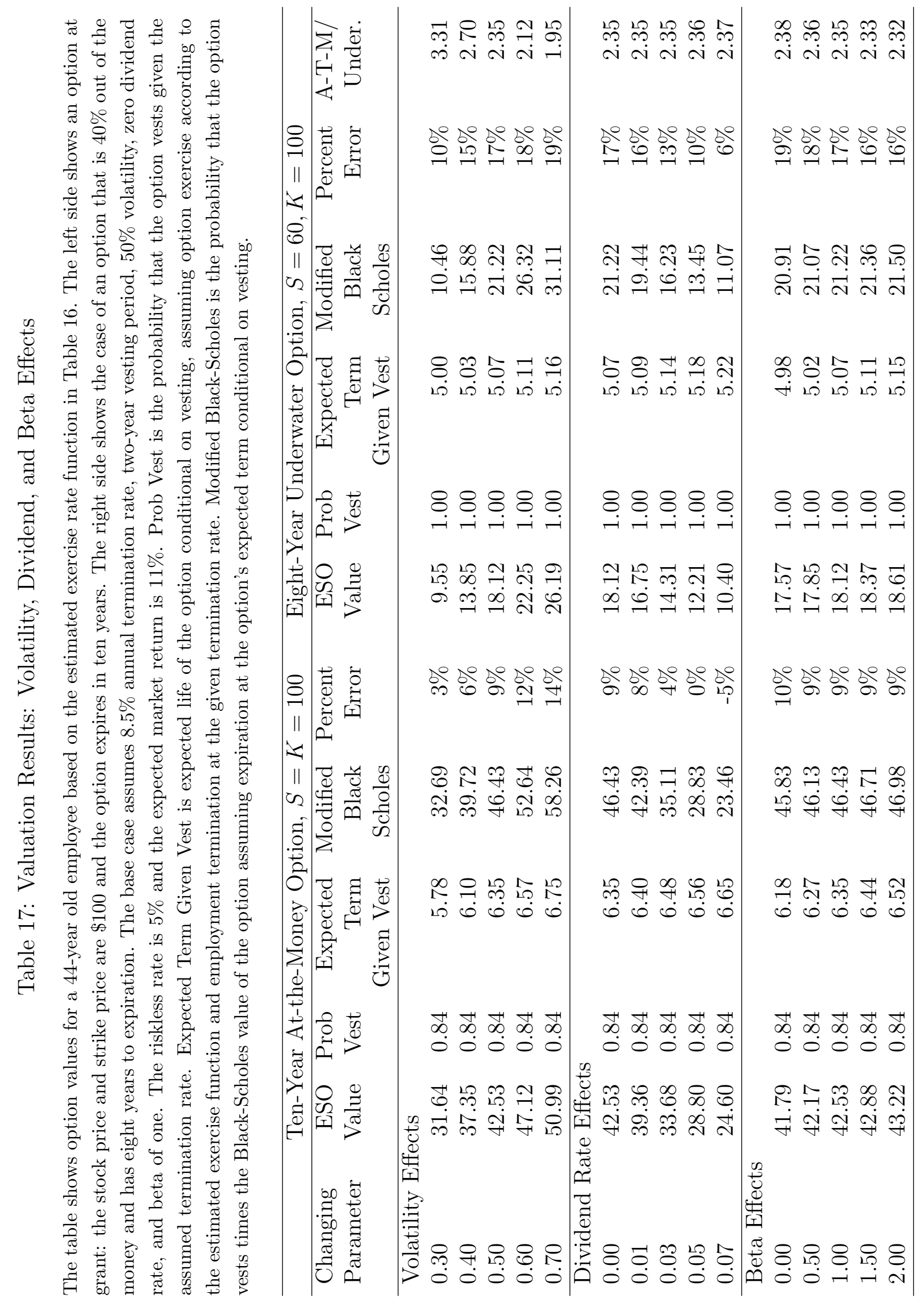




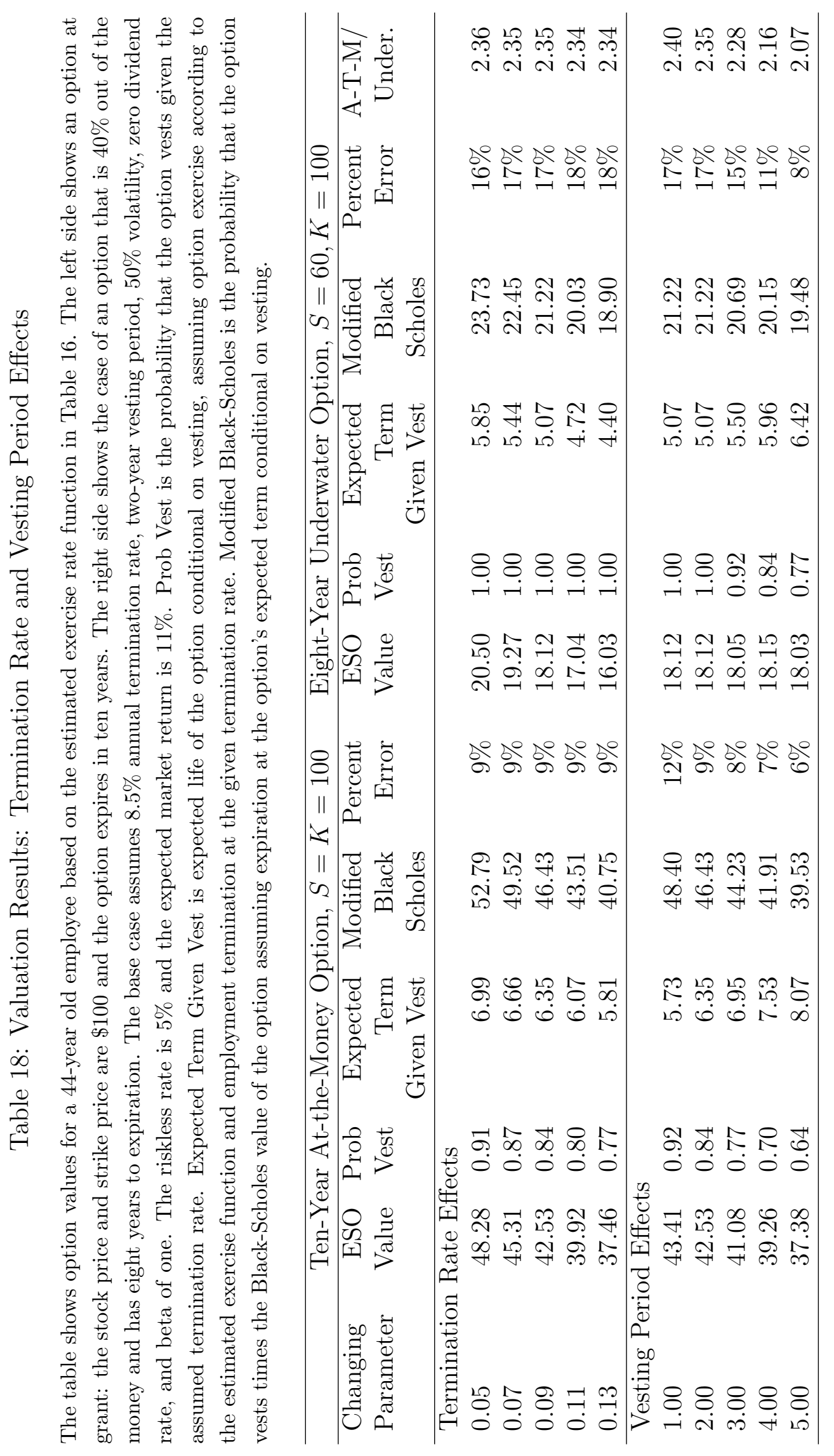




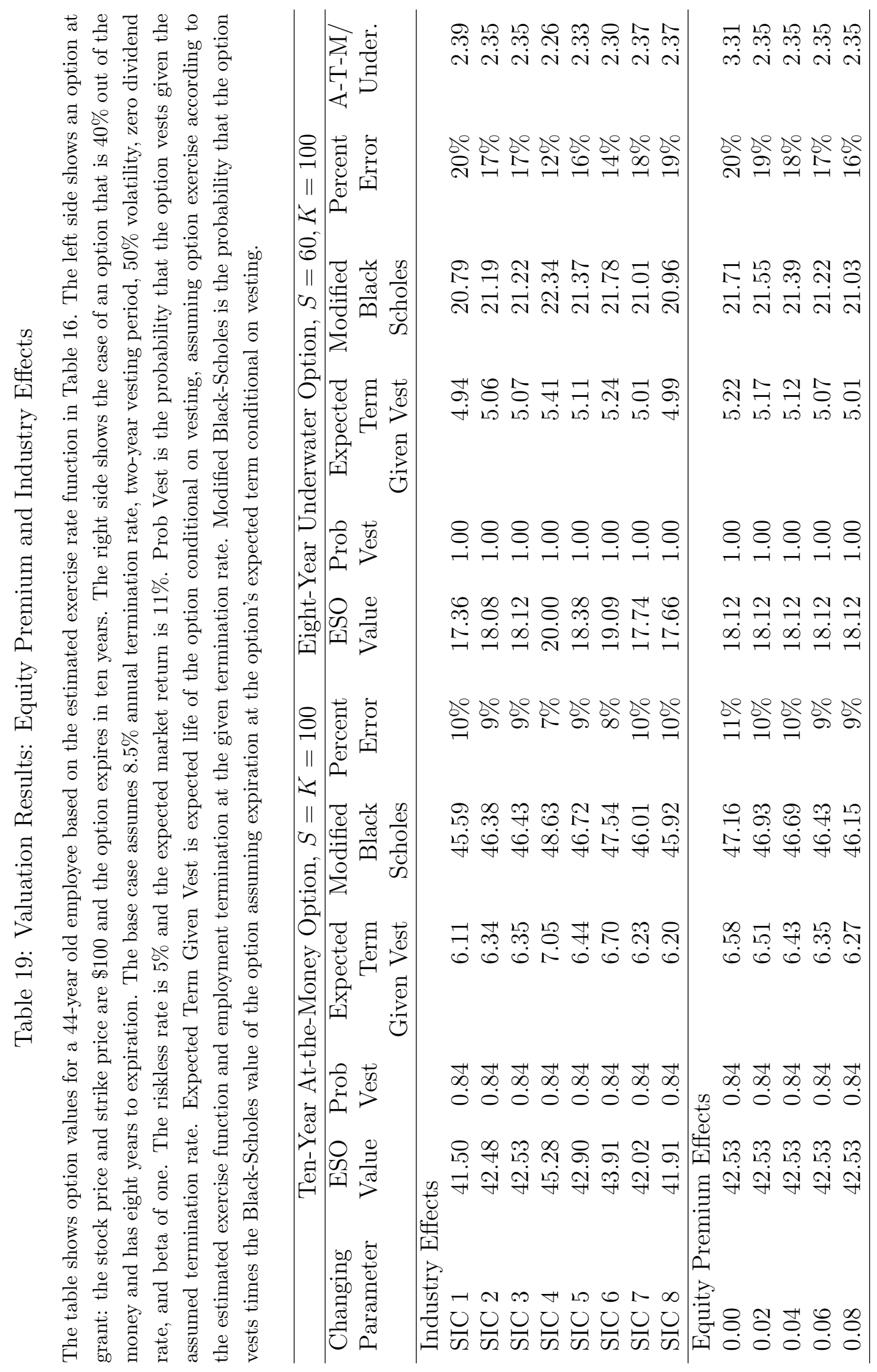

